\title{
Retinoic Acid Attenuates $\beta$-Amyloid Deposition and Rescues Memory Deficits in an Alzheimer's Disease Transgenic Mouse Model
}

\author{
Yun Ding, ${ }^{1,2}$ Aimin Qiao, ${ }^{4}$ Ziqing Wang, ${ }^{2}$ J. Shawn Goodwin, ${ }^{5}$ Eun-Sook Lee, ${ }^{4}$ Michelle L. Block, ${ }^{3}$ Matthew Allsbrook, ${ }^{2}$ \\ Michael P. McDonald, ${ }^{6}$ and Guo-Huang Fan ${ }^{1,2}$ \\ ${ }^{1}$ Department of Veterans Affairs Medical Center, Richmond, Virginia 23249, Departments of 2 Pharmacology and Toxicology and ${ }^{3}$ Anatomy and \\ Neurobiology, Virginia Commonwealth University School of Medicine, Richmond, Virginia 23298, Departments of ${ }^{4}$ Neurobiology and Neurotoxicology and \\ ${ }^{5}$ Cancer Biology, Meharry Medical College, Nashville, Tennessee 37208, and ${ }^{6}$ Department of Neurology, the University of Tennessee Health Science Center, \\ Memphis, Tennessee 38163
}

Recent studies have revealed that disruption of vitamin A signaling observed in Alzheimer's disease (AD) leads to $\beta$-amyloid (A $\beta$ ) accumulation and memory deficits in rodents. The aim of the present study was to evaluate the therapeutic effect of all-trans retinoic acid (ATRA), an active metabolite of vitamin A, on the neuropathology and deficits of spatial learning and memory in amyloid precursor protein (APP) and presenilin 1 (PS1) double-transgenic mice, a well established AD mouse model. Here we report a robust decrease in brain $\mathrm{A} \beta$ deposition and tau phosphorylation in the blinded study of APP/PS1 transgenic mice treated intraperitoneally for 8 weeks with ATRA $(20 \mathrm{mg} / \mathrm{kg}$, three times weekly, initiated when the mice were 5 months old). This was accompanied by a significant decrease in the APP phosphorylation and processing. The activity of cyclin-dependent kinase 5, a major kinase involved in both APP and tau phosphorylation, was markedly downregulated by ATRA treatment. The ATRA-treated APP/PS1 mice showed decreased activation of microglia and astrocytes, attenuated neuronal degeneration, and improved spatial learning and memory compared with the vehicle-treated APP/ PS1 mice. These results support ATRA as an effective therapeutic agent for the prevention and treatment of AD.

Key words: retinoic acid; Alzheimer's disease; neurodegeneration; $\beta$-amyloid; memory; amyloid precursor protein

\section{Introduction}

Alzheimer's disease $(\mathrm{AD})$ is the most common form of dementia in the elderly. This disease is characterized by extracellular neuritic plaques composed of fibrillar $\beta$-amyloid $(\mathrm{A} \beta)$ peptide and intracellular neurofibrillary tangles containing hyperphosphorylated tau (Selkoe, 2001). A $\beta$ peptides are generated by successive proteolysis of $\beta$-amyloid precursor protein (APP), a large transmembrane glycoprotein that is initially cleaved by the $\beta$-site APPcleaving enzyme 1 (BACE1) and subsequently by $\gamma$-secretase in the transmembrane domain (De Strooper et al., 1998; Vassar et al., 1999; Edbauer et al., 2003). Phosphorylation of APP at its C-terminal Thr668 facilitates its processing (Cruz et al., 2006). Although the aggregated $\mathrm{A} \beta$ peptides are believed to play a central role in AD pathology (Chen et al., 2000; Apelt and Schliebs, 2001; Götz et al., 2001; Walsh et al., 2002), the cause of AD re-

Received July 8, 2008; revised Aug. 28, 2008; accepted Sept. 10, 2008.

This work was supported by a Veterans Affairs Merit award (G.-H.F.), Specialized Neuroscience Research Program Grant U54NS041071-06 from National Institutes of Health, and startup funds from Virginia Commonwealth University School of Medicine (G.-H.F.). We thank Dr. Diana Marver at Meharry-Vanderbilt Alliance for helpful discussion and Marjelo Mines and Kurt Watson for technical assistance in behavioral studies. The Imaging Core at Virginia Commonwealth University School of Medicine and the Morphology Core at Meharry Medical College provided technical assistance for confocal microscopy, stereology, and wide-field microscopy.

Correspondence should be addressed to Dr. Guo-Huang Fan, Department of Pharmacology and Toxicology, Virginia Commonwealth University School of Medicine, Richmond, VA 23298. E-mail: ghfan@vcu.edu.

DOI:10.1523/JNEUROSCI.3153-08.2008

Copyright $\odot 2008$ Society for Neuroscience ～0270-6474/08/2811622-13\$15.00/0 mains elusive. Thus, the development of novel therapeutic approaches is desperately needed.

Retinoic acid (RA), the active metabolite of vitamin A (retinoid), has been shown to control the expression of genes related to APP processing (Lahiri et al., 1995; Yang et al., 1998; Hong et al., 1999; Culvenor et al., 2000; Satoh and Kuroda, 2000). RA regulates gene expression through its nuclear receptors: the RA receptors (RARs) and retinoid X receptors (RXRs) (Mangelsdorf and Evans, 1995). Deprivation of vitamin A results in $A \beta$ accumulation (Corcoran et al., 2004), loss of hippocampal long-term potentiation (LTP) (Misner et al., 2001), and memory deficits in rodents (Cocco et al., 2002; Etchamendy et al., 2003), all of which are hallmarks of AD. Mice that carry mutated versions of RAR and/or RXR receptors also show deficits in spatial learning and memory (Chiang et al., 1998; Wietrzych et al., 2005). The impairment in spatial learning and memory and the depression of synaptic plasticity that occurs in vitamin A-deprived rodents also occur during aging in rodents (Etchamendy et al., 2001). Both effects are reversed by the administration of RA (Etchamendy et al., 2001, 2003). Importantly, clinical evidence has shown defective retinoid transport and function in AD brain (Goodman and Pardee, 2003), suggesting that increasing the availability of RA in the brain may prevent or decrease $\mathrm{A} \beta$-associated neurodegeneration (Goodman and Pardee, 2003; Goodman, 2006; Maden, 2007). However, to date, there has been no conclusive experi- 
mental evidence obtained from $\mathrm{AD}$ animal models to show a therapeutic effect of RA on AD.

In the present study, we examined the effect of all-trans RA (ATRA) treatment on the neurodegenerative pathology and memory deficits in APP and presenilin 1 (PS1) double-transgenic mice, a well established AD mouse model (Moolman et al., 2004; Trinchese et al., 2004; Zhang et al., 2005). When systemically administered to 5-month-old APP/PS1 mice for 8 weeks, ATRA effectively reduced $\mathrm{A} \beta$ accumulation and tau hyperphosphorylation. More intriguingly, ATRA treatment of the APP/PS1 mice significantly alleviated glial activation and neuronal loss in the brain and rescued the spatial learning and memory deficits.

\section{Materials and Methods}

Transgenic mice and ATRA treatment. APP/PS1 double-transgenic mice used in this study were obtained from The Jackson Laboratory [strain name, B6C3-Tg(APPswe,PSEN1dE9)85Dbo/J; stock number 004462]. These mice express a chimeric mouse/human APP containing the K595N/M596L Swedish mutations and a mutant human PS1 carrying the exon 9-deleted variant under the control of mouse prion promoter elements, directing transgene expression predominantly to CNS neurons (Jankowsky et al., 2001, 2004). The two transgenes cosegregate in these mice. APP/PS1 mice were maintained as double hemizygotes by crossing with wild-type mice on a B6C3F1/J background strain (stock number 100010; The Jackson Laboratory) and were genotyped by PCR analysis of genomic DNA from tail biopsies. All animals were housed according to standard animal care protocols and maintained in a pathogen-free environment at Virginia Commonwealth University. The animals were randomized for therapy trials and coded, and the operators and data analyzer remained double blinded to which treatment they received, until the code was broken at the completion of data collection.

Male APP/PS1 transgenic mice and wild-type littermates were randomly assigned into four groups: treated APP/PS1 mice, untreated APP/ PS1 mice, treated wild-type mice, and untreated wild-type mice. Treated groups received ATRA (Sigma-Aldrich) dissolved in normal saline containing 5\% DMSO three times weekly by intraperitoneal injection (20 $\mathrm{mg} / \mathrm{kg}$ ). Untreated groups received an equal volume of 5\% DMSO as a vehicle control. Treatment was started when the mice were 5 months old and was continued for 8 weeks. The dose and duration of ATRA, whose pharmacokinetics has been extensively studied in rodents (Wang et al., 1980; Kalin et al., 1981), were chosen based on pilot studies and a review of literature (Iyoda et al., 2007). The use of 5-month-old APP/PS1 mice to receive the ATRA treatment is based on previous reports demonstrating that these mice begin to have $\mathrm{A} \beta$ plaques as early as 2.5 months of age and have a high $\mathrm{A} \beta$ load in hippocampal and cortical subareas from 6 months of age (Blanchard et al., 2003; Trinchese et al., 2004).

Morris water maze test. After the ATRA treatment for 8 weeks, the spatial learning and memory were evaluated by the Morris water maze test (Morris, 1984). The Morris water maze is a circular and galvanized water tank ( $120 \mathrm{~cm}$ diameter $\times 50 \mathrm{~cm}$ height) filled to a depth of $25 \mathrm{~cm}$ with water. The surface area of the tank was divided into four equal quadrants. The water was made opaque by addition of milk powder, and its temperature was adjusted to $24 \pm 1^{\circ} \mathrm{C}$. An escape platform $(10 \mathrm{~cm}$ diameter) was placed in one of the four maze quadrants submerged $2 \mathrm{~cm}$ below the water surface $(30 \mathrm{~cm}$ away from the side wall). The platform was kept at the same (target) quadrant during the entire course of the experiment. The mice were required to find the hidden platform using only distal spatial cues available in the testing room. Conditions were constant throughout the experiments. The mice were gently released into the water, always facing the tank wall. A different starting position was used on each trial. They were given $120 \mathrm{~s}$ to find the platform. On reaching the platform, the mice were allowed to remain on it for $10 \mathrm{~s}$. They were taken out, dried, and placed in a separate cage for $\sim 60 \mathrm{~min}$ before the next trial. If a mouse failed to locate the platform within $120 \mathrm{~s}$, it was assisted by the experimenter and allowed to stay there for the same period of time (10 s). Between the trials, the water was stirred to erase olfactory traces of previous swim patterns. The animals were trained for four trials per day for 5 consecutive days to locate and escape onto the platform, and their spatial learning scores (latency in seconds) were recorded.

To assess memory consolidation, a probe trial was performed $2 \mathrm{~d}$ after the $5 \mathrm{~d}$ acquisition tests. In this trial, the platform was removed from the tank, and the mice were allowed to swim freely. For these tests, time spent in the target quadrant within $90 \mathrm{~s}$ was recorded. The time spent in the target quadrant was taken to indicate the degree of memory consolidation that has taken place after learning. The time spent in the target quadrant was used as a measure of spatial memory. All time measurements were performed by using a stopwatch by an experimenter blinded to which experimental group to which each animal belonged.

Immunohistochemistry. After the above behavioral study, animals were anesthetized with an intraperitoneal injection of ketamine $(0.05 \mathrm{mg} / \mathrm{kg})$ and perfused first with PBS and then with $4 \%$ paraformaldehyde in PBS. The brains were dehydrated in three steps of 2-h-long intervals in 70, 96, and $99 \%$ ethanol solutions, respectively. The brains were then left in xylene overnight before being embedded in paraffin. Paraffin blocks were horizontally sectioned with a microtome setting of 6 or $50 \mu \mathrm{m}$. The sections were floated on a warm water bath and mounted on SuperFrostPlus (Menzel-Glazer) glass slides. With a section interval of 12, one series of sections was collected in a systematic random manner from each animal. Each series contained 14-16 sections. Sections were kept overnight at $37^{\circ} \mathrm{C}$ and then stored at room temperature until staining.

Immunohistochemical procedures were performed using coronal sections as described above. Paraffin-embedded brain sections were deparaffined, rehydrated and endogenous peroxidase quenched with hydrogen peroxide $[1 \%(\mathrm{v} / \mathrm{v})$ in methanol], and microwaved for $5 \mathrm{~min}$ (with $650 \mathrm{~W}$ ) in citrate buffer (10 mm sodium citrate, $\mathrm{pH} 6$ ). They were then incubated for $60 \mathrm{~min}$ in blocking buffer [10\% (v/v) goat normal serum (Millipore Bioscience Research Reagents) in PBS containing 0.1\% (v/v) Triton X-100 (Sigma)] and subsequently in appropriately diluted primary antibodies (overnight at $4^{\circ} \mathrm{C}$ ). After rinsing, the primary antibody was developed by incubating with cyanine 3 (Cy3)- or FITC-conjugated secondary antibodies against the corresponding species $(1 \mathrm{~h}$ at room temperature) or by incubating with biotinylated secondary antibodies against the corresponding species ( $1 \mathrm{~h}$ at room temperature). This was followed by $\mathrm{DAB}$ (Vector Laboratories) using the instructions of the manufacturer for peroxidase labeling.

The following antibodies were used for immunohistochemistry. A $\beta$ plaques were immunostained with a mouse monoclonal anti-A $\beta_{42}$ (6E10; Signet). Astrocytes were stained with a rabbit polyclonal glial fibrillary acidic protein (GFAP) antibody (DakoCytomation). Microglia were stained with a rabbit polyclonal Iba-I antibody (Wako Pure Chemicals). For neurons, antibodies against two markers were used: presynaptic terminals were labeled with a rabbit polyclonal synaptophysin (SYN) antibody (Millipore Bioscience Research Reagents), and neuronal cell bodies and dendrites were labeled with a rabbit polyclonal microtubule associated protein 2 (MAP2) antibody (Millipore Bioscience Research Reagents). Cell nuclei were stained with a mouse monoclonal antibody against heterogeneous nuclear ribonucleoprotein U (hnRNP-U) (Santa Cruz Biotechnology). Primary antibodies were applied at dilutions of 1:3000 for GFAP, 1:1000 for MAP2, SYN, and hnRNP-U, and 1:200 for Iba-I.

Histochemistry. Paraffin-embedded brain sections were deparaffined, rehydrated, and stained with Campbell-Switzer silver AD stain (NeuroScience Associates), a highly sensitive marker of $A \beta$ deposits. A detailed protocol for this stain was kindly provided by Dr. Bob Switzer of NeuroScience Associates (Knoxville, TN). Briefly, deparaffinized slides are placed into a pyridine silver solution for the induction of nucleation sites, followed by incubation in a physical developer solution for $15 \mathrm{~min}$, rinsed in gold chloride solution, and fixed in 1\% thiosulfate solution.

Image analysis and semiquantification of immunofluorescence. Images for the DAB staining and Campbell-Switzer staining were acquired with a Nikon TE2000-E inverted microscope, whereas immunofluorescent images were acquired with a Nikon TE2000-U confocal microscope under $40 \times$ oil immersion objective with numerical aperture (NA) 1.4, zoom 1.6. Fluorochromes were excited using a $488 \mathrm{~nm}$ argon laser for FITC and a $543 \mathrm{~nm}$ helium-neon laser for $\mathrm{Cy} 3$, and the detector slits were configured to minimize any crosstalk between the channels. Semiquantitative analysis of mean fluorescence intensities (MFIs) of MAP2 and 
SYN immunofluorescence was performed using NIH Image J software. Eight images of slides stained for MAP2 or SYN were obtained per hippocampal CA1 and CA3 regions, respectively. Collaged images of MAP2 and SYN staining were converted into a 8-bit format, and the background was subtracted. An intensity threshold was set and was kept constant for all images analyzed. MFI per square micrometer area was calculated by dividing the MFI units by the area of outlined regions and are presented as a bar graph.

Stereology. The stereological setup consisted of an Olympus BH-2 microscope (Olympus Life and Material Science Europe) with a high numerical aperture (NA 1.40) and oil immersion $100 \times$ objectives, which allows focusing in a thin focal plane inside a thick section. A camera transmits the image to a monitor on which a counting frame is superimposed using the computer-assisted stereological CAST-GRID software (Visiopharm). A motorized automatic stage was used to control movement in the $x-y$ plane via a connected joystick. Movement in the $z$-axis was done manually with the focus button on the microscope, and the distance between the upper and lower surfaces of the sections and the height of the disectors were measured with a Heidenhain microcator (model VRZ 401) with a precision of $0.5 \mu \mathrm{m}$.

The number of $\mathrm{A} \beta$ plaques, SYN immunoreactive presynaptic boutons (SIPBs), neurons, astrocytes, and microglia in the hippocampal and/or cortical regions were counted using the optical fractionator method of unbiased stereological cell counting techniques. $A \beta$ plaques or cells were sampled in counting frames of 644-988 $\mu \mathrm{m}^{2}$ [a(frame)] moved in $x$ and $y$ steps of $100 \times 100 \mu \mathrm{m}$ [ $a$ (step)]. The area sampling fraction (asf) was calculated as $a$ (frame) $/ a$ (step). The thickness sampling fraction (tsf) was calculated as the height of the optical disector probe $(h)$ ( 8 or $10 \mu \mathrm{m})$ divided by the average height of the sections $(t)(\mathrm{tsf}=h / t)$. A $\beta$ plaques were counted using a $20 \times$ immersion lens, whereas neurons, astrocytes, or microglia were counted using a $40 \times$ oil-immersion lens (NA 1.4) and were included in the measurement only when they came into focus within the disector (disector height of $20 \mu \mathrm{m}$ and average thickness of mounted sections of $50 \mu \mathrm{m}$; thickness was measured at random intervals throughout every section and estimated by the software program). Total A $\beta$ plaque or cell number $(N)$ was estimated using the following equation: $N=Q-\times 1 / \operatorname{tsf} \times 1 /$ asf $\times 1 /$ ssf, where $Q-$ is the number of cells counted, and ssf is the section sampling fraction. In the case of clusters of $A \beta$ plaques or microglia, each cluster was counted as one plaque or cell and identified by the most clearly defined nucleus. Coefficients of error and variation were calculated as described previously (Wirenfeldt et al., 2003).

The same sections that were sampled for number estimates were used to estimate volume of $\mathrm{A} \beta$ plaques, neuronal bodies, microglia, and astrocytes in cortical or hippocampal regions. The system software superposed a point grid at random over low-power $(2.5 \times)$ magnified images of each section. Total reference volume $\left(V_{\text {ref }}\right)$ was estimated using the Cavalieri-point counting method (Gundersen and Jensen, 1987), based on the sum of points that hit on each reference space, as follows: $V_{\text {ref }}=$ $\sum P \times a(p) \times t \times k$, where $\sum P$ is the sum of points on the grid hitting the reference space, $a(p)$ is the area per point on the grid, $t$ is the mean section thickness (in millimeters), and $k$ is the sampling interval. The same $a(p)$ was used for estimating volume for both the cortical and hippocampal regions.

The densities of $\mathrm{A} \beta$ plaques, microglia, astrocytes, and SIPBs (number per cubic millimeter) were calculated by dividing the number counted by the total volume sampled of each reference space. The volume of sampled reference space was the number of disectors multiplied by the volume of one disector.

Western blot analysis. Brain tissues were homogenized in TBS (20 mM Tris- $\mathrm{HCl}$ buffer, $\mathrm{pH}$ 7.4, $150 \mathrm{~mm} \mathrm{NaCl})(0.150 \mathrm{~g}$ tissue/2 $\mathrm{ml}$ buffer $)$ containing a mixture of protease inhibitors, including $0.5 \mathrm{~mm}$ phenylmethylsulfonyl fluoride, $20 \mu \mathrm{g} / \mathrm{ml}$ aprotinin, $20 \mu \mathrm{g} / \mathrm{ml}$ leupeptin, 20 $\mu \mathrm{g} / \mathrm{ml}$ pepstatin, and $1 \mathrm{~mm}$ EDTA (all inhibitors obtained from Sigma). Homogenates were sonicated briefly and centrifuged at $15,000 \times g$ for 30 $\mathrm{min}$. Protein concentration in the supernatants was determined with the BCA protein assay (Pierce). SDS supernatants ( $10 \mu \mathrm{g}$ of protein per lane) were run on $10 \%$ SDS polyacrylamide gel under reducing conditions. Proteins were transferred to a polyvinylidene difluoride (GE Healthcare) membrane $(300 \mathrm{~mA}$ for $2 \mathrm{~h}$ ). The membrane was blocked with $3 \%$ dry milk in $0.1 \%$ Tween 20/TBS for $1 \mathrm{~h}$ and then incubated for $2 \mathrm{~h}$ at room temperature with the specific antibodies. After washing, blots were incubated with the corresponding HRP-labeled secondary antibodies (1:2000 dilution) for $1 \mathrm{~h}$. Labeling was detected using the ECL system (GE Healthcare). Blots were stripped following the instructions of the manufacturer (GE Healthcare) and subsequently labeled with $\beta$-actin antibody (1:10,000; Sigma) following the same procedures as above. Bands were analyzed using densitometric software (Scion Image).

The following antibodies were used for Western blot: mouse monoclonal anti-phosphorylated (p)-APP (Thr668) (1:1000; Cell Signaling Technology), rabbit polyclonal anti-APP-C-terminal fragments (CTFs) (Sigma), mouse monoclonal anti-p-tau (Ser519) (1:500; Abcam), rabbit polyclonal anti-p-tau (Ser235) (1:1000; Santa Cruz Biotechnology), rabbit polyclonal anti-p-tau (Ser404) (1:1000; Santa Cruz Biotechnology), rabbit polyclonal anti-p-tau (Ser396) (1:1000; Santa Cruz Biotechnology), rabbit polyclonal anti-p-tau (Thr205) (1:1000; Santa Cruz Biotechnology), mouse monoclonal anti-cyclin-dependent kinase 5 (CDK5) (1: 1000; Santa Cruz Biotechnology), mouse monoclonal anti-p-CDK5 (Ser159) (1:200; Santa Cruz Biotechnology), mouse monoclonal anti-pglycogen synthase kinase $3 \beta$ (GSK3 $\beta$ ) (Ser9) (1:1000; Santa Cruz Biotechnology), mouse monoclonal anti-GSK3 $\alpha, \beta$ (Tyr279/216) (1:1000; ECM Biosciences), rabbit polyclonal anti-p35/25 (1:1000, Santa Cruz Biotechnology), rabbit polyclonal anti-tau (1:1000; Santa Cruz Biotechnology), rabbit polyclonal anti-tau-1 (1:1000; Santa Cruz Biotechnology), mouse monoclonal anti-GSK3 $\beta$ (1:4000; Sigma), mouse monoclonal anti- $\beta$-actin (1: 4000; Sigma), and mouse monoclonal anti-GFAP (1:15,000; DakoCytomation).

Statistical analysis. Data are expressed as the mean \pm SEM. Analyses were performed using a two-way ANOVA followed by Fisher's least significant difference post hoc analysis to identify significant effects. Differences were considered significant at $p<0.05$.

\section{Results \\ ATRA treatment prevents $A \beta$ plaque accumulation in APP/PS1 mice}

RA has been shown to inhibit formation of fibrillar $A \beta$ from fresh $\mathrm{A} \beta$ in vitro (Ono et al., 2004). However, its effect on $\mathrm{A} \beta$ deposition in a transgenic AD mouse model has not been documented. We tested the effect of systemic administration of ATRA on A $\beta$ deposition in APP/PS1 double-transgenic mice, which start to exhibit $\mathrm{A} \beta$ plaques as early as 2.5 months of age (Blanchard et al., 2003 ) and have moderate levels of preexisting $A \beta$ deposits when the mice are 5 months old (based on our pilot study). Therefore, ATRA treatment was initiated when the mice were 5 months old, and treatment of 5\% DMSO in saline (vehicle) or ATRA in vehicle continued for 8 weeks. The results demonstrated that ATRA treatment significantly attenuated $\mathrm{A} \beta$ levels in both the frontal cortex and hippocampus (Fig. 1A,B). Stereological analysis of multiple stained sections also revealed a significant decrease in $\mathrm{A} \beta$ deposition. The plaque number, average volume of the plaques, and area occupied by the $\mathrm{A} \beta$ plaques were all reduced significantly in both the frontal cortex and hippocampus compared with the vehicle-treated APP/PS1 mice (Fig. 1C,D). Noticeably, 8 weeks of vehicle treatment had no significant effect on $A \beta$ deposition in APP/PS1 mice compared with the untreated ageand gender-matched APP/PS1 mice (data not shown). These data suggest a specific inhibitory effect of ATRA on $A \beta$ deposition.

\section{ATRA prevents APP processing and phosphorylation of both APP and tau, likely through inhibition of CDK5 expression}

The involvement of APP in the mechanism of $A \beta$ deposition is well documented (Neve et al., 1990). APP is cleaved by BACE1 enzyme at the $\mathrm{N}$-terminal region, producing membrane-bound C-terminal fragments (APP-CTFs) (Evin et al., 2003). APPCTFs are considered potential early markers for the biological 
A
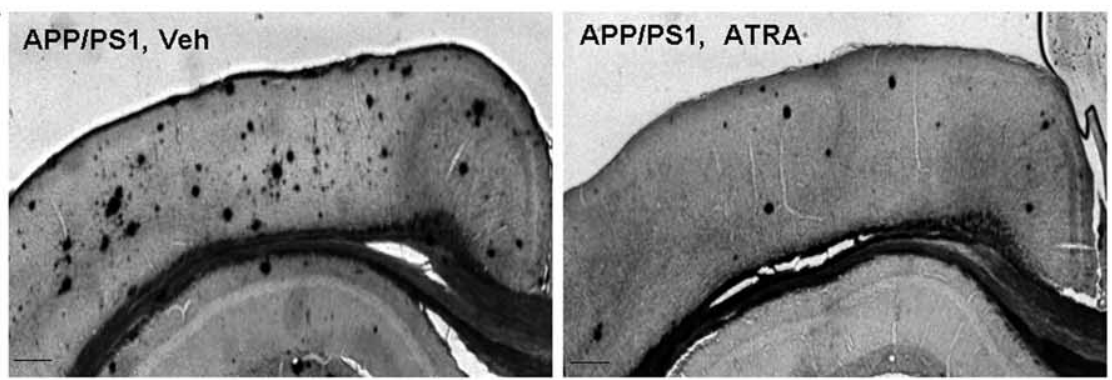

B
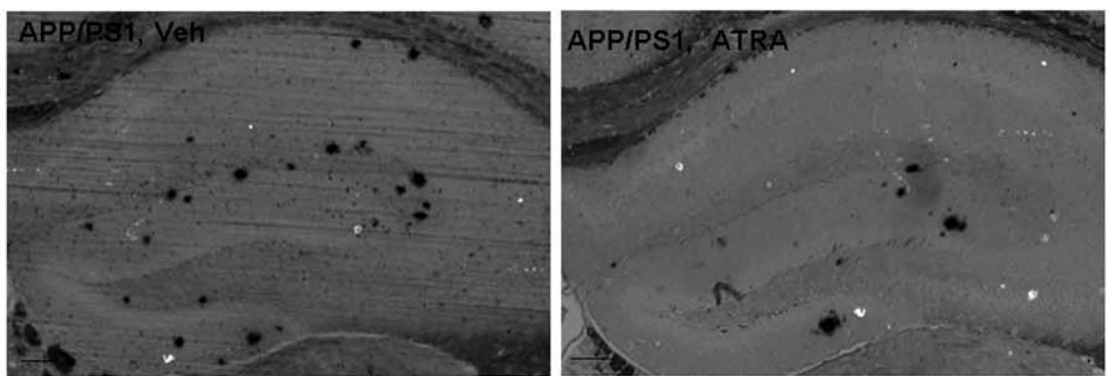

C

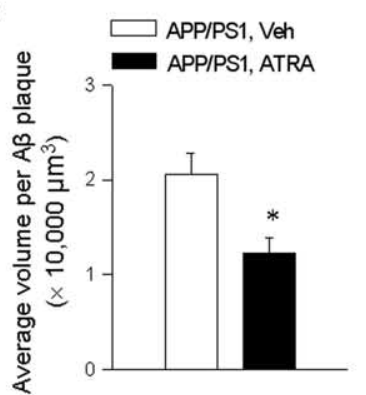

D
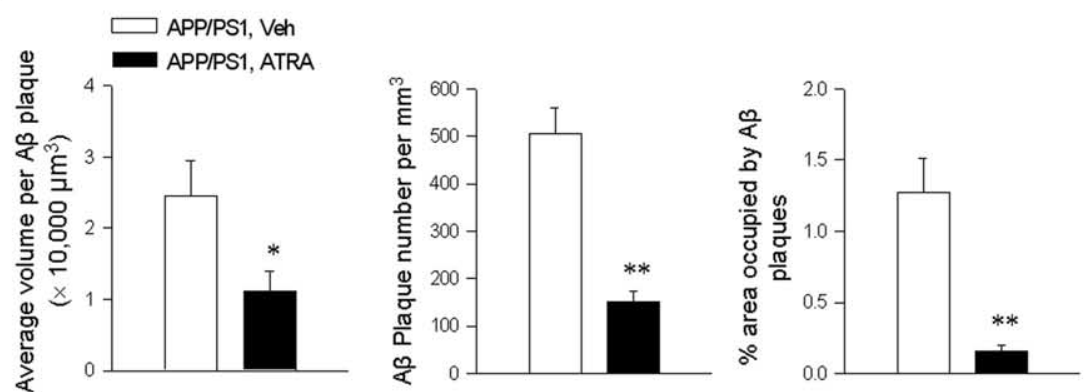

Figure 1. ATRA-treated APP/PS1 mice exhibit reduced levels of $A \beta$ deposits compared with vehicle-treated (Veh) APP/PS1 mice. $\boldsymbol{A}, \boldsymbol{B}$, Representative images of Campbell-Switzer staining in frontal cortex $(\boldsymbol{A})$ and hippocampus $(\boldsymbol{B})$ in APP/PS1 mice treated with vehicle as control (left) or ATRA (right). Scale bars, $200 \mu \mathrm{m}$. C, D, Stereological quantification of A $\beta$ volume (left), number (middle), and area occupied by $A \beta$ plaques (right) in frontal cortex ( $\boldsymbol{C}$ and hippocampus $(\boldsymbol{D})$ as described in Materials and Methods. Values from multiple images of each section that cover most to all the region of study were averaged per animal per experiment. Data are mean \pm SEM from six mice per genotype. ${ }^{*} p<0.05,{ }^{* *} p<0.01$ versus vehicle-treated control APP/PS1 mice.

diagnosis of AD (Sergeant et al., 2002). To determine whether ATRA influences the production of APP-CTFs, brain tissues from vehicle- or ATRA-treated APP/PS1 mice or wild-type littermates were subjected to a Western blot analysis using an antiCTF antibody, which also recognizes the full-length APP. As shown in Figure $2 \mathrm{~A}$ (row 1), a significant decrease in the production of APP-CTFs was observed in the ATRA-treated APP/PS1 mice compared with the vehicle-treated APP/PS1 mice. Quantitative analysis showed an $\sim 70 \%$ reduction in the frontal cortex and a $50 \%$ reduction in the hippocampus (Fig. $2 \mathrm{~B}$ ). In contrast, the vehicle-treated APP/PS1 mice did not show a significant difference in the production of CTFs compared with the untreated age- and gender-matched APP/ PS1 mice (data not shown), suggesting a specific inhibitory effect of ATRA on APP processing.

The antibody against APP-CTFs used in this study also recognized the fulllength APP (Fig. 2A, row 1). Although APP expression was slightly reduced in the ATRA-treated wild-type mice compared with the vehicle-treated wild-type mice, no significant difference in APP expression levels was observed between the APP/ PS1 mice treated with ATRA and vehicle (Fig. 2A, row 1). Similarly, we did not observe a significant difference in the levels of BACE1 between the groups (Fig. $2 \mathrm{~A}$, row 2). This result is not surprising because a previous study also showed a modest difference in the BACE1 expression between APP/PS1 mice and wild-type controls (Ohno et al., 2006). These findings suggest that ATRA influences APP processing via a mechanism beyond modulating the expression of APP and BACE1.

Given the important role of APP phosphorylation at C-terminal Thr668 in its processing (Lee et al., 2003) and neurodegeneration (Chang et al., 2006), we determined APP phosphorylation in the brain tissues by Western blotting using an antibody against phospho-Thr668 of APP. As shown in Figure 2 A (row 3), a robust elevation of phosphorylated APP was detected in the vehicle-treated APP/PS1 mice. In contrast, the APP phosphorylation was significantly reduced in the ATRA-treated APP/PS1 mice (Fig. 2A, row 3). Quantitative analysis shows an $\sim 70 \%$ decrease in the frontal cortex and $60 \%$ decrease in the hippocampus in the ATRA-treated APP/PS1 mice compared with the vehicle-treated APP/PS1 mice (Fig. 2C).

Hyperphosphorylated tau appears in the APP/PS1 mouse brain after the onset of $\mathrm{A} \beta$ deposition (Kurt et al., 2003). Tau, a substrate for several protein kinases (Singh et al., 1994; Johnson and Hartigan, 1999), is phosphorylated at over 38 serine/threonine residues in $\mathrm{AD}$ (MorishimaKawashima et al., 1995; Hanger et al., 1998). Given the beneficial role of ATRA in APP processing and A $\beta$ deposition, we attempted to determine a possible role of ATRA treatment in tau hyperphosphorylation in APP/PS1 mice. Tau hyperphosphorylation was assessed by Western blotting using antibodies against different phosphorylation sites on tau, including Thr205, Ser235, Ser 396, Ser404, and Ser519. As shown in Figure $2 \mathrm{~A}$ (rows 4-8), a robust enhancement of tau phosphorylation at all these sites was observed in both the frontal cortex and hippocampus of the vehicle-treated APP/PS1 mice. In contrast, 


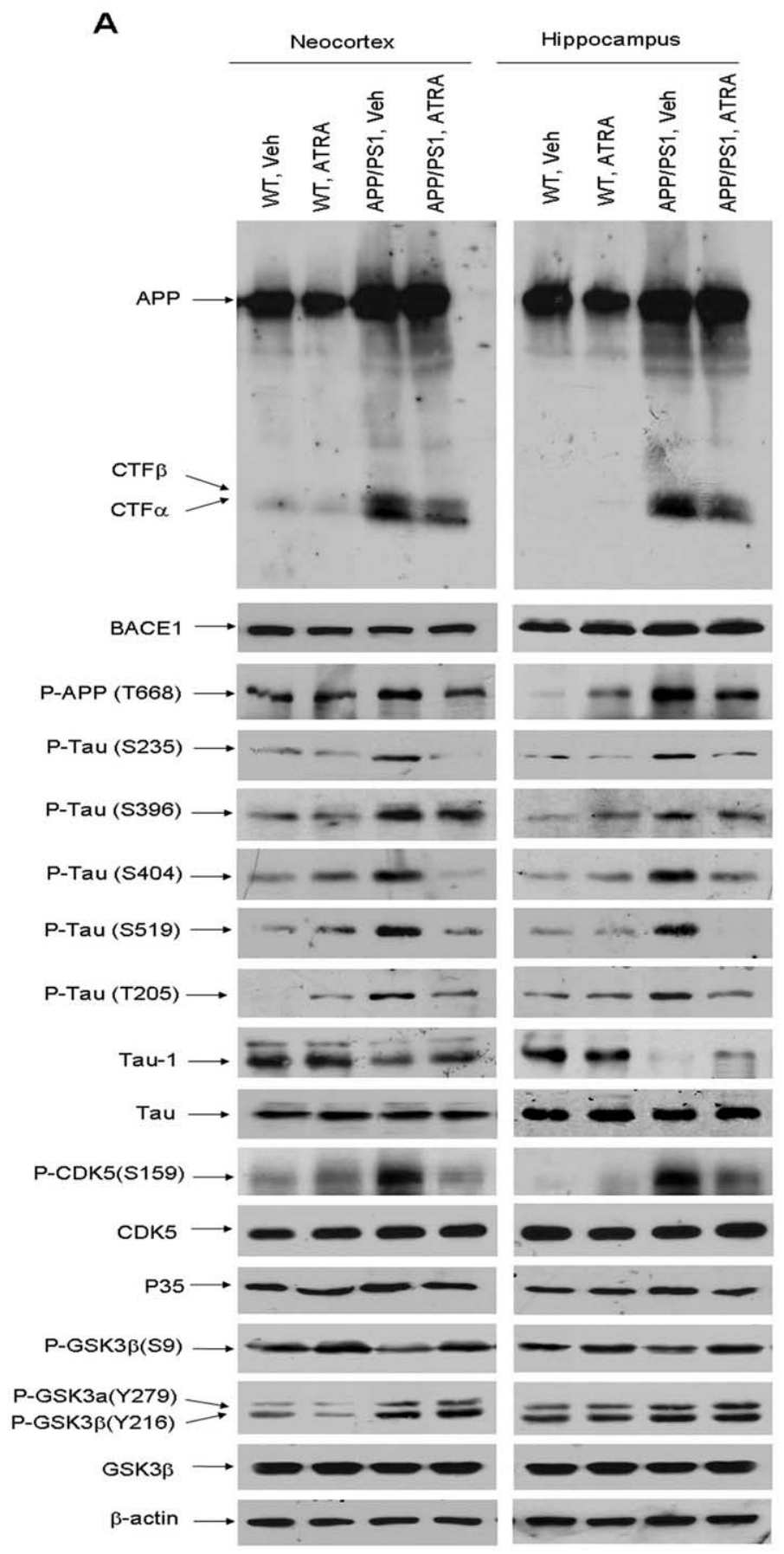

B
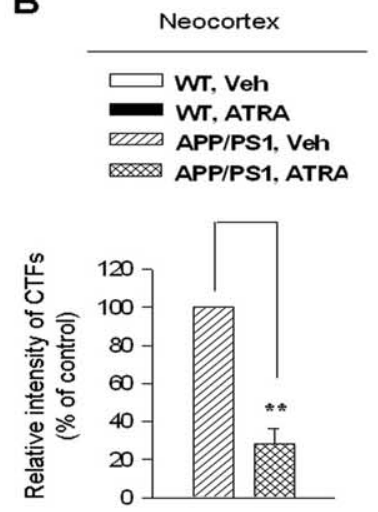

\section{C}
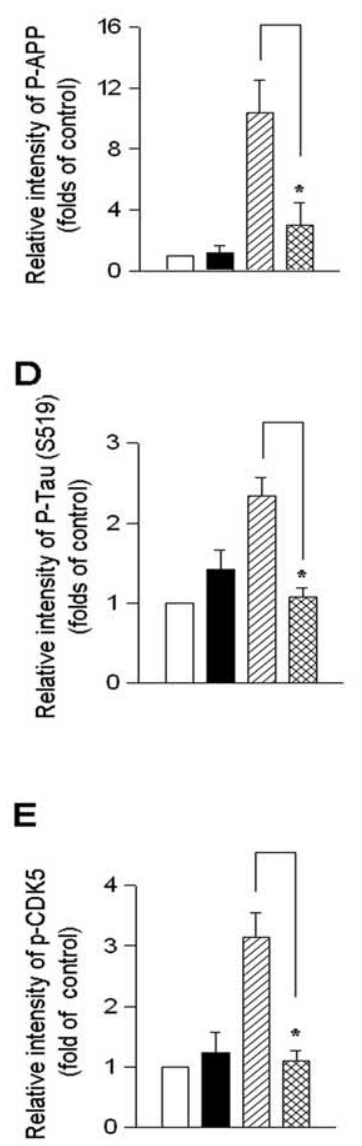
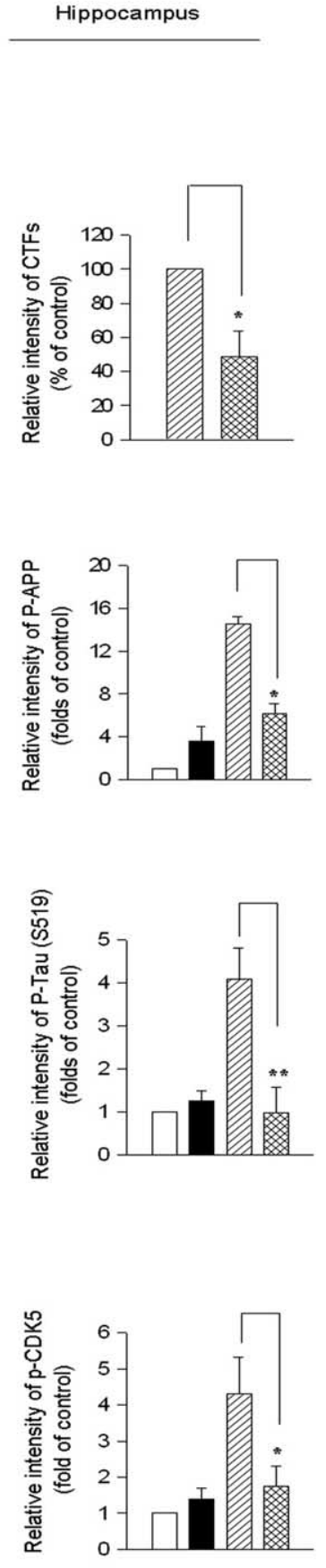

Figure 2. ATRA treatment decreased the production of APP-CTFs, phosphorylation of APP and Tau, and expression of CDK5 in APP/PS1 mice. A, Representative Western blots of APP, APP-CTFs, BACE1, phosphorylated APP (Thr668), phosphorylated Tau at Ser519, Ser202, Ser235, Ser396, and Ser404, tau-1, total tau, phosphorylated CDK5 (Ser159), p35, CDK5, phosphorylated GSK3 $\beta$ (Ser9), phosphorylated GSK3 $\alpha, \beta$ (Tyr216), and GSK3 $\beta$ in cortical and hippocampal lysates of wild-type or APP/PS1 mice treated with vehicle and ATRA, respectively. $\boldsymbol{B}-\boldsymbol{E}$, Quantitative analysis of APP-CTFs $(\boldsymbol{B})$, phosphorylated tau (D), phosphorylated APP $(\boldsymbol{C})$, and CDK5 $(\boldsymbol{E})$ from wild-type or APP/PS1 mice treated with vehicle (Veh) or ATRA. In all experiments, quantified results were normalized to $\beta$-actin expression. Values are expressed as percentages or folds of the values from the vehicle-treated APP/PS1 mice (set to $100 \%)$ and are the mean \pm SEM ( $n=6$ animals of each group). ${ }^{*} p<0.05 ;{ }^{* *} p<0.01$.

except for a slight decrease in the phosphorylation at Ser396, a robust decrease in the tau phosphorylation at Ser235, Ser404, Ser519, and Thr205 was observed in the both the frontal cortex and hippocampus of the ATRA-treated APP/PS1 mice. Quantitative analysis of the Western blot bands of the phosphorylated tau at Ser519 indicated an $~ 50 \%$ decrease in the tau phosphorylation in the frontal cortex and a 75\% decrease in the hippocampus in the ATRA-treated APP/PS1 mice relative to vehicle-treated
APP/PS1 mice (Fig. 2D). Both of these decreases represented a return to wild-type levels. In addition, Western blotting with a tau-1 antibody, recognizing the nonphosphorylated tau at Ser198/Ser199/Ser202, showed a significant decrease in the tau-1 immunoreactivity in the brain tissues of the vehicle-treated APP/ PS1 mice compared with the wild-type controls (Fig. 2A, row 9), consistent with a previous report (Zhou et al., 2008). A slight increase in the tau-1 immunoreactivity was observed in the 
ATRA-treated APP/PS1 mice (Fig. 2A, row 9). No significant difference in the total tau levels was revealed between the groups (Fig. $2 A$, row 10).

Among the several kinases involved in tau hyperphosphorylation (Singh et al., 1994; Johnson and Hartigan, 1999), CDK5 and GSK $3 \beta$ have been most implicated in the abnormal hyperphosphorylation of tau (Imahori and Uchida, 1997; Shelton and Johnson, 2004; Iqbal et al., 2005). Both kinases phosphorylate tau at a large number of sites, most of which are common to the two enzymes (Wang et al., 1998; Anderton et al., 2001). Moreover, CDK5 and GSK3 $\beta$ are the key kinases responsible for the APP phosphorylation (Aplin et al., 1996; Iijima et al., 2000). Given the inhibitory role of ATRA in the phosphorylation of both tau and APP, we attempted to determine whether ATRA plays a role in regulating CDK5 and/or GSK3 $\beta$. It is known that GSK3 $\beta$ is activated through the phosphorylation at Tyr216 or is inhibited when Ser9 is phosphorylated (Cohen and Frame, 2001) and that CDK5 requires both $\mathrm{p} 35$ binding and phosphorylation at Ser159 for maximal rates of activation (Sharma et al., 1999). Thus, we examined the levels of phosphorylated CDK5 and GSK3 $\beta$ using specific antibodies, respectively, and the levels of p35 using a C-terminal polyclonal antibody that recognizes full-length p35 as well as the cleaved product, p25. As shown in Figure 2 A (row 11), a robust enhancement of CDK5 phosphorylation at Ser159 was observed in the brains of the vehicle-treated APP/PS1 mice compared with the wild-type controls. Strikingly, the ATRA-treated APP/PS1 mice showed a remarkable decrease in the phosphorylation of CDK5 (Fig. 2A, row 11) compared with the vehicletreated APP/PS1 mice. Quantitative analysis of the Western blot bands indicated an $\sim 50 \%$ decrease in the phosphorylated CDK5 in the frontal cortex and a $60 \%$ decrease in the hippocampus in the ATRA-treated APP/PS1 mice relative to vehicle-treated APP/ PS1 mice (Fig. 2E). As expected, the elevated levels of p35 observed in the vehicle-treated APP/PS1 mice were reversed by the ATRA treatment (Fig. 2A, row 12). We did not observe a difference in the total CDK5 levels between the groups (Fig. $2 \mathrm{~A}$, row 13). These data suggest that ATRA treatment downregulates CDK5 activity.

Western blot analysis with an antibody against the phosphorylated GSK $3 \alpha, \beta$ (Tyr279/216) showed an enhancement of GSK $3 \beta$ phosphorylation in both the hippocampus and frontal cortex in the vehicle-treated APP/PS1 mice compared with the wild-type controls (Fig. $2 \mathrm{~A}$, row 14). However, no significant difference in the GSK3 $\beta$ (Tyr216) phosphorylation was observed between the ATRA- and vehicle-treated APP/PS1 mice (Fig. 2 A, row 14). Similarly, although a significant increase in the phosphorylation of GSK3 $\alpha$ at Tyr279 was observed in the brains of the vehicle-treated APP/PS1 mice relative to the wild-type controls, no significant difference was observed between the ATRA- and vehicle-treated APP/PS1 mice (Fig. $2 A$, row 14). Interestingly, Western blot analysis with an antibody against the phosphorylated GSK3 $\beta$ (Ser9) showed a marked decrease in the phosphorylation of GSK3 $\beta$ at Ser9 in the vehicle-treated APP/PS1 mice relative to the wild-type controls (Fig. $2 A$, row 15 ). In contrast, a marked reversal of the decreased phosphorylation of GSK $3 \beta$ at Ser9 was observed in the ATRA-treated APP/PS1 mice (Fig. 2 A, row 15). These results suggest that ATRA has a modest inhibitory effect on GSK $3 \beta$ activity.

\section{ATRA treatment inhibits activation of microglia and astrocytes in APP/PS1 mice}

In the brains of human $\mathrm{AD}$ patients and transgenic $\mathrm{AD}$ mouse models, infiltration of activated astrocytes and microglia are seen in the area of $\mathrm{A} \beta$ plaques (Itagaki et al., 1989; Frautschy et al., 1998; Stalder et al., 1999; Bornemann et al., 2001; Matsuoka et al., 2001), which are characteristic components of an inflammatory process that develops around injury in the brain (McGeer and McGeer, 1999). Based on previous in vitro studies showing that RA inhibited the neurotoxic effect of activated microglia by suppressing the production of inflammatory cytokines and cytotoxic molecules (Dheen et al., 2005), we compared astrocytic and microglial reactivity in APP/PS1 mice treated with ATRA or vehicle as a control.

The activated astrocytes were visualized via confocal microscopy using brain sections coimmunostained with a GFAP antibody, an astrocyte marker, and an hnRNP-U antibody, which is a nuclear marker. Immunostaining against GFAP demonstrated a marked increase of reactive astrocytes in the brains of the vehicletreated control APP/PS1 mice (Fig. $3 A$ ). In contrast, the GFAP immunoreactivity was markedly decreased in the ATRA-treated APP/PS1 mice (Fig. 3A). The hnRNP-U immunostaining indicated no significant difference in astrocyte number between the groups (Fig. 3A). To visualize the reactive astrocytes surrounding the $\mathrm{A} \beta$ plaques, $\mathrm{A} \beta$ plaques were stained with the CampbellSwitzer staining method followed by immunostaining of GFAP. As shown in Figure $3 B$, accumulation of reactive astrocytes surrounding the $\mathrm{A} \beta$ plaques was evident in the brains of the vehicletreated control APP/PS1 mice (left panel), whereas both the size of $A \beta$ plaques and astrocytic reactivity were decreased in the brains of ATRA-treated APP/PS1 mice (right panel). These results were confirmed by stereological analysis of GFAP immunoreactivity in the hippocampus, which showed an $\sim 45 \%$ decrease in the astrocytic volume in the ATRA-treated APP/PS1 mice relative to the vehicle-treated APP/PS1 mice (Fig. 3C), whereas no significance difference in the astrocyte number was observed between the groups (Fig. 3D). The change in the astrocytic reactivity was also confirmed by Western blot analysis of GFAP. A marked elevation of GFAP expression was observed in the hippocampal tissues of the control APP/PS1 mice (Fig. 3E). In contrast, the ATRA-treated APP/PS1 mice showed a markedly reduced GFAP expression (Fig. 3E). Quantitative analysis showed a 50\% decrease in GFAP expression in the ATRA-treated APP/PS1 mice relative to that in the control APP/PS1 mice (Fig. $3 F$ ).

The activated microglia were visualized by the immunostaining of Iba-I. As shown in Figure 4A, a significant elevation of Iba-I immunoreactivity was observed in the vehicle-treated APP/ PS1 mice compared with the vehicle-treated wild-type mice. Strikingly, a significantly less Iba-I immunoreactivity was observed in the ATRA-treated APP/PS1 mice relative to the vehicletreated APP/PS1 mice. Because the staining for microglia displayed high variability among mice of the same group, these results were tested and confirmed using another marker of microglia, HLA-DR (for human leukocyte antigen-D region related; data not shown).

Double staining of Iba-I and $\mathrm{A} \beta$ plaques showed reactive microglia around the $\mathrm{A} \beta$ plaques in the brains of vehicle-treated control APP/PS1 mice, whereas fewer reactive microglia were observed around the smaller and less $A \beta$ plaques in the brains of ATRA-treated APP/PS1 mice (Fig. $4 B$ ). These results were confirmed by stereological analysis of Iba-I immunostaining in the hippocampus, which showed an $\sim 60 \%$ decrease in the microglial volume in the ATRA-treated APP/PS1 mice relative to the vehicle-treated APP/PS1 mice (Fig. 4C). No significant difference in the microglia number was observed between the groups (Fig. $4 D$ ), suggesting a significant decrease in microglia activation in the brains of ATRA-treated APP/PS1 mice. 
A
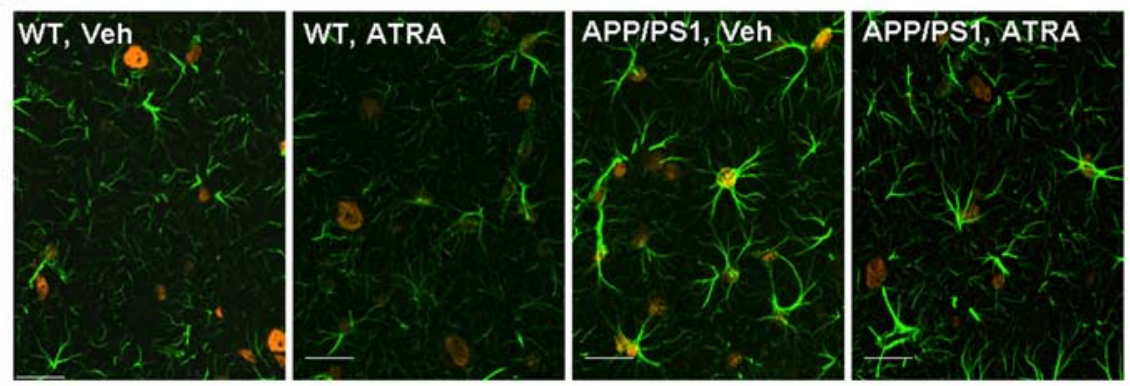

B
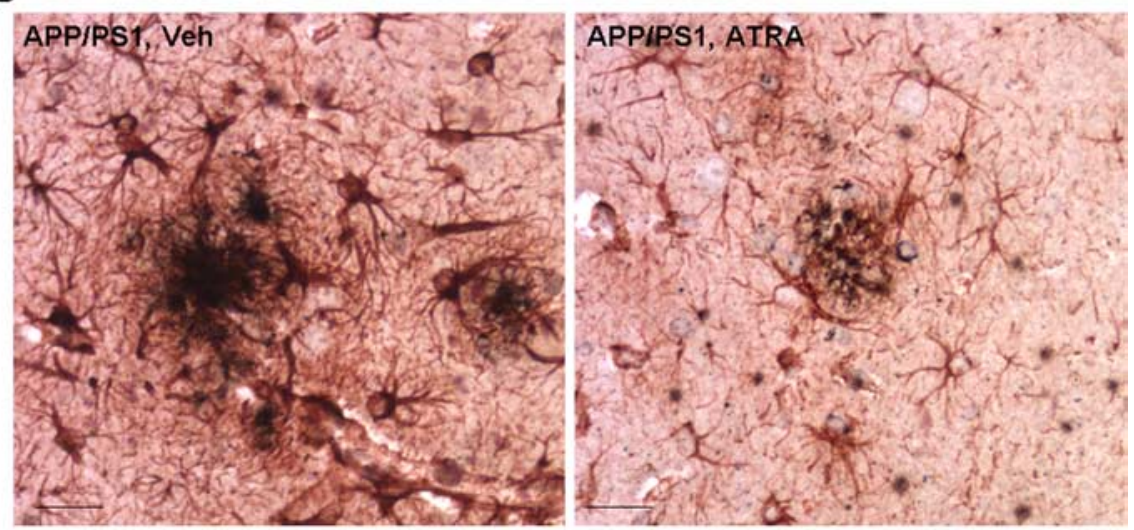

C
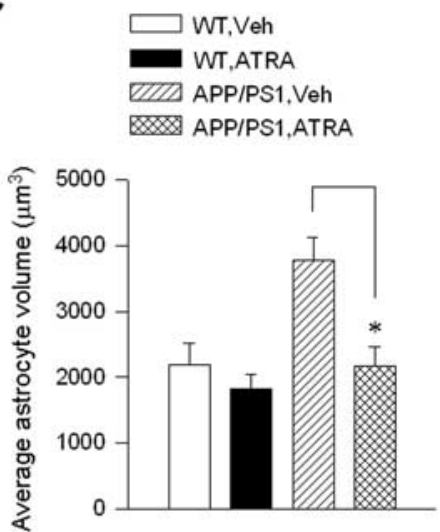

E

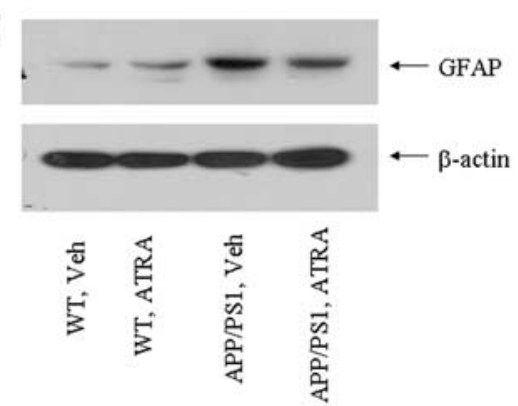

D
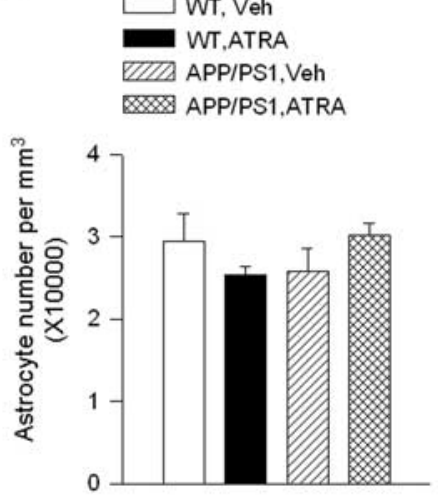

$\mathbf{F}$

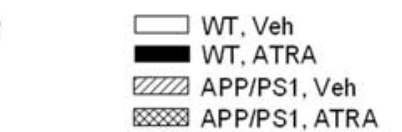

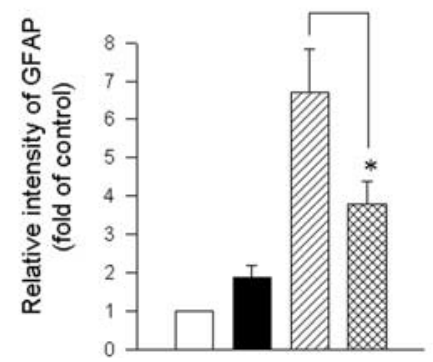

Figure 3. ATRA treatment results in a decrease in astrocytic reactivity in the brains of APP/PS1 mice. $A$, Fluorescent GFAP (green)/hnRNP-U (red) colocalization in the hippocampal CA3 region of APP/PS1 mice and wild-type mice (WT) treated with vehicle (Veh) or ATRA. Scale bar, $20 \mu \mathrm{m}$. B, Double staining of GFAP and A $\beta$ plaques (Campbell-Switzer staining) showed less activated astrocytes surrounding the $A \beta$ plaques in the hippocampal CA3 region of the ATRA-treated APP/PS1 mice (right) than that of the vehicle-treated control APP/PS1 mice (left). Scale bar, $20 \mu \mathrm{m}$. C, Quantification of astrocyte volume in the hippocampus by unbiased stereology. Mean value of each animal per group is the average of values from two to three experiments (total of 3-6 sections). Error bars represent means \pm SEM from six mice per group. $D$, Quantification of astrocyte number in the hippocampus by unbiased stereology. Mean value of each animal per group is the average of values from two to three experiments

\section{ATRA treatment attenuates}

neurodegeneration in APP/PS1 mice

Neuronal degeneration and loss observed in the brains of $\mathrm{AD}$ patients (West et al., 1994) and in the brains of APP/PS1 transgenic mice (Fonseca et al., 2004; Rutten et al., 2005) is hypothesized to be exacerbated by an inflammatory reaction (McGeer and McGeer, 1999). Given the inhibitory effect of ATRA on glial activation, an indicator of CNS inflammation, we determined the effect of ATRA on neuronal integrity. For this purpose, we examined the levels of two neuronal markers, SYN, expressed on the presynaptic vesicles, and MAP2, expressed on the neuronal cell bodies and dendrites, in the brains of wildtype and APP/PS1 mice treated with vehicle or ATRA.

The immunoreactivity of SYN, a robust marker for functional neurons, was analyzed with both semiquantification and unbiased stereological quantification. The semiquantitative results indicated that the density of SIPBs was markedly decreased in the CA3 subfield of the hippocampus in the vehicle-treated APP/PS1 mice compared with the vehicle-treated wild-type controls (Fig. $5 A, B$ ), consistent with a previous report (Rutten et al., 2005). The decreased density of SIPBs was completely reversed in the ATRA-treated APP/PS1 mice compared with the vehicle-treated APP/PS1 mice (Fig. 5A,B). Double staining of SYN and $A \beta$ plaques showed a robust decrease in the number of SIPBs surrounding the $A \beta$ plaques in the hippocampal dentate gyrus of vehicle-treated APP/PS1 mice (Fig. 5C, left). Correlated with the few or no $A \beta$ deposits seen in this region in the ATRA-treated APP/PS1 mice, more enriched SIPBs were observed in the ATRA-treated APP/PS1 mice (Fig. $5 C$, right). The unbiased stereological quantification showed an $\sim 50 \%$ reduction in the number of SIPBs in the hippocampus of the vehicle-treated APP/PS1 mice compared with the vehicle-treated wild-type controls (Fig. 5D). No significant difference in SIPB number was observed between the vehicle-treated and untreated APP/PS1 mice (data not

(total of 3-6 sections). Error bars represent group means \pm SEM from six mice per group. $\boldsymbol{E}$, Representative Western blot of GFAP and $\beta$-actin in brain lysates of wild-type and APP/PS1 mice treated with vehicle or ATRA. $\boldsymbol{F}$, Densitometric quantification of GFAP protein levels of wild-type and APP/PS1 mice treated with vehicle or ATRA ( $n=3$ per group). Values were expressed relative to control (wild-type micetreated with vehicle). Error bars represent means \pm SEM of three mice per group. ${ }^{*} p<$ 0.05 versus vehicle-treated control APP/PS1 mice. 
A
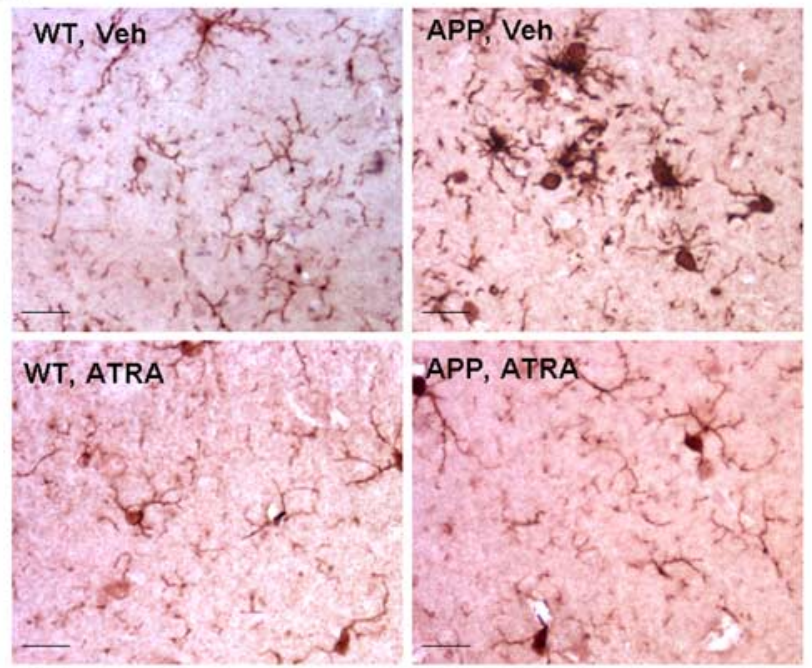

B

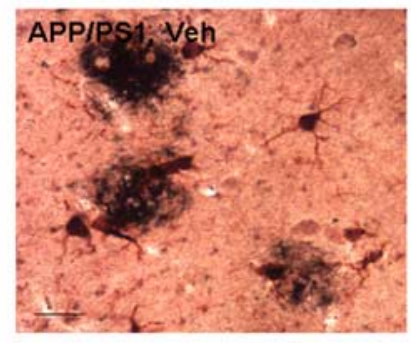

C

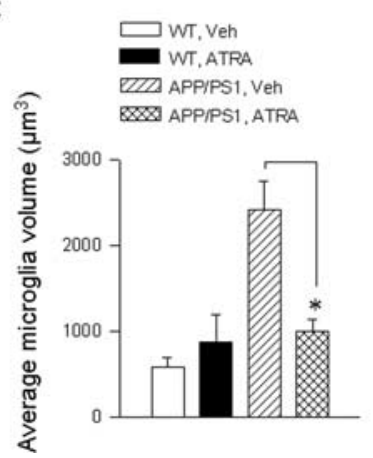

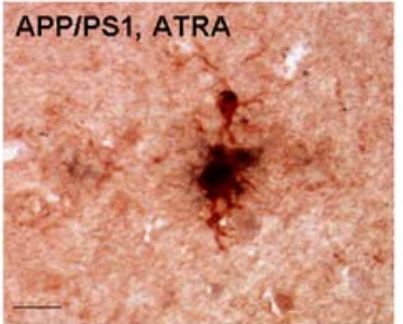

D

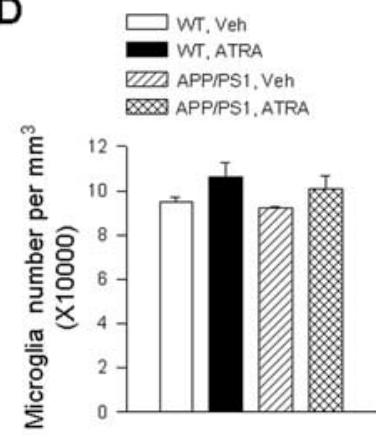

Figure 4. ATRA treatment results in a decrease in microglial reactivity in the brains of APP/ PS1 mice. $A$, Representative immunostaining of lba-l in the hippocampal CA3 region of APP/PS1 mice and wild-type mice (WT) treated with vehicle or ATRA. Scale bar, $20 \mu \mathrm{m}$. $\boldsymbol{B}$, Double staining of lba-I and $A \beta$ plaques (Campbell-Switzer staining) showing less activated microglia surrounding the $A \beta$ plaques in the hippocampal CA3 region of ATRA-treated (right) than the vehicle-treated (left) control APP/PS1 mice. Scale bar, $20 \mu \mathrm{m}$. C, Quantification of microglia volume in the hippocampus by unbiased stereology. Mean value of each animal per group is the average of values from two to three experiments (total of 3-6 sections). Error bars represent means \pm SEM from six mice per group. $D$, Quantification of microglia number in the hippocampus by unbiased stereology. Mean value of each animal per group is the average of values from two to three experiments (total of 3-6 sections). Error bars represent means \pm SEM from six mice per group. ${ }^{*} p<0.05$ versus vehicle-treated control APP/PS1 mice.

shown). Rather, the ATRA-treated APP/PS1 mice showed a complete rescue of the loss of SIPBs in the hippocampus (Fig. 5D). These data suggest that ATRA decreases synaptic loss in the APP/ PS1 mice.

The immunoreactivity of MAP2 in the neuronal cell bodies and/or dendrites was analyzed with both semiquantification (to measure the MFIs of neuronal bodies and dendrites) and unbiased stereological quantification (to measure the number of neurons and volume of neuronal bodies). Consistent with a previous

report showing decreased MAP2 immunoreactivity in the hippocampus of APP/PS1 mice (Fonseca et al., 2004), our semiquantitative results showed that the vehicle-treated APP/PS1 mice had a dramatic decrease $(50 \%)$ in MAP2 reactivity in the pyramidal neurons of the CA1 region of the hippocampus compared with the vehicle-treated wild-type controls (Fig. $6 A, B$ ). Intriguingly, the ATRA-treated APP/PS1 mice showed 80\% more MAP2 immunoreactivity than the vehicle-treated APP/PS1 mice (Fig. $6 A, B)$. Double staining of MAP 2 and $\mathrm{A} \beta$ plaques showed a significant degeneration of neurons, characterized by damage or loss of neuronal fibers surrounding the plaques in the frontal cortex of the vehicle-treated APP/PS1 mice (Fig. 6C, left). In contrast, a significant improvement in the integrity of the neuronal fibers surrounding the smaller $\mathrm{A} \beta$ plaques was observed in the frontal cortex of the ATRA-treated APP/PS1 mice (Fig. 6C, right). Stereological quantification of the MAP2 immunopositive neurons in the frontal cortex indicated no significant difference in the neuronal number between the groups (Fig. 6D), but there was a significant decrease in the volume of neuronal bodies in the vehicle-treated APP/PS1 mice compared with that in the vehicletreated wild-type mice (Fig. 6 E). The reduced neuronal volume seen in the vehicle-treated APP/PS1 mice was reversed in the ATRA-treated APP/PS1 mice (Fig. 6E). These data suggest that ATRA treatment decreases the rate of neuronal degeneration in APP/PS1 mice.

\section{ATRA treatment rescues deficits of learning and memory in APP/PS1 mice}

The APP/PS1 AD mouse model is well known to develop $\mathrm{A} \beta$ associated cognitive deterioration with increasing age (Trinchese et al., 2004). Consistently, our study demonstrated that the vehicle-treated APP/PS1 mice showed impaired acquisition of spatial learning, as assessed by the Morris water maze test, the most widely accepted behavioral test of hippocampus-dependent spatial learning and memory (Morris, 1984). These mice were impaired in learning to use the available visuospatial cues to locate the submerged escape platform, as indicated by slower improvements in the escape latency across consecutive trials (Fig. $7 A$ ). In contrast, ATRA-treated APP/PS1 mice were able to locate the escape platform, as demonstrated by significantly reduced escape latency across trials (Fig. 7A). Furthermore, we confirmed that ATRA treatment not only significantly promoted learning during the hidden-platform trials but also significantly improved memory retention during the probe trial (Fig. $7 B$ ). In the Morris water maze, observed deficits in the acquisition phase of place learning and in the probe trial were not attributable to noncognitive factors, because APP/PS1 mice and wild-type mice displayed identical swimming speeds and escape latencies on the visible platform trails. In the present study, ATRA treatment did not affect the swimming ability of the APP/PS1 mice, as reflected by their similar swimming speeds between the groups (data not shown). These findings support the hypothesis that ATRA may benefit spatial memory deficits in APP/PS1 mice selectively, through the attenuation of $\mathrm{A} \beta$-associated neurodegeneration.

\section{Discussion}

Although RA has been suggested as a potential therapeutic approach to prevent or decrease $\mathrm{A} \beta$-associated neurodegeneration (Goodman and Pardee, 2003; Goodman, 2006; Maden, 2007), the actual therapeutic role of RA in AD pathology and dementia has not yet been ascertained. Our findings indicate that ATRA treatment, for as little as 8 weeks, inhibits and possibly reverses accumulation of $\mathrm{A} \beta$ deposits and tau hyperphosphorylation in 
APP/PS1 double-transgenic mice. The ATRA-treated APP/PS1 mice showed significantly decreased levels of activated glial markers, elevated levels of neuronal markers in cortical and/or hippocampal regions, and improved spatial learning and memory, when compared with the vehicle-treated APP/PS1 mice.

The inhibitory effect of ATRA on $A \beta$ accumulation is likely attributable to its inhibition of APP processing, because the production of APP-CTFs, the direct precursor of $A \beta$ (Evin et al., 2003), was attenuated by the ATRA treatment. In addition, a previous study has shown that ATRA prevents formation of fibrillar $A \beta$ from fresh A $\beta$ (Ono et al., 2004), suggesting that ATRA is involved in multiple steps of $A \beta$ deposition. APP processing can be modulated by different mechanisms, including but not limited to an altered APP expression as well as expression/function of BACE1, a major $\beta$-secretase involved in APP processing. However, we did not observe a significant difference in the expression of APP or BACE1 between the groups. This is in contrast with a previous report showing that ATRA reversed the downregulation of APP, BACE1, and APPCTFs in the brain of rats deprived of vitamin A (Husson et al., 2006). This discrepancy suggests that RA differentially influences APP expression under diverse conditions.

It has been shown that Thr668 phosphorylation facilitates the $\beta$-secretase cleavage of APP and increases A $\beta$ generation (Lee et al., 2003). Based on the observation that ATRA-treatment reversed the elevation of APP phosphorylation in APP/ PS1 mice, we postulate that ATRA may prevent APP processing by inhibiting its phosphorylation. Among the several protein kinases phosphorylating APP at Thr668 in vitro or in vivo (Suzuki et al., 1994; Iijima et al., 2000; Standen et al., 2001), CDK5 is believed to be a key kinase responsible for APP phosphorylation in neuronal cells (Iijima et al., 2000; Liu et al., 2003; Wen et al., 2008a), compatible with our result showing a concomitant downregulation of CDK5 activity by ATRA treatment in the APP/PS1 transgenic mice. However, we cannot exclude the possible involvement of other pathways modulated by CDK5 in the inhibitory effect of ATRA on A $\beta$ accumulation. For instance, p25 overexpression results in enhanced forebrain $\mathrm{A} \beta$ levels, likely attributable to axonal transport dysfunction (Stokin et al., 2005; Cruz et al., 2006). Based on the observation that ATRA treatment reduced the levels of $\mathrm{p} 35$, we propose that ATRA attenuates $\mathrm{A} \beta$ accumulation via regulating axonal transport of $A \beta$. In addition, $\mathrm{p} 25 / \mathrm{CDK} 5$ has been shown to participate in transcriptional regulation of BACE1, leading to enhanced amyloidogenic processing (Wen et al., 2008b). Unexpectedly, ATRA treatment did not affect BACE1 expression, albeit p35/CDK5 was downregulated. This discrepancy may be attributable to different animal models used.
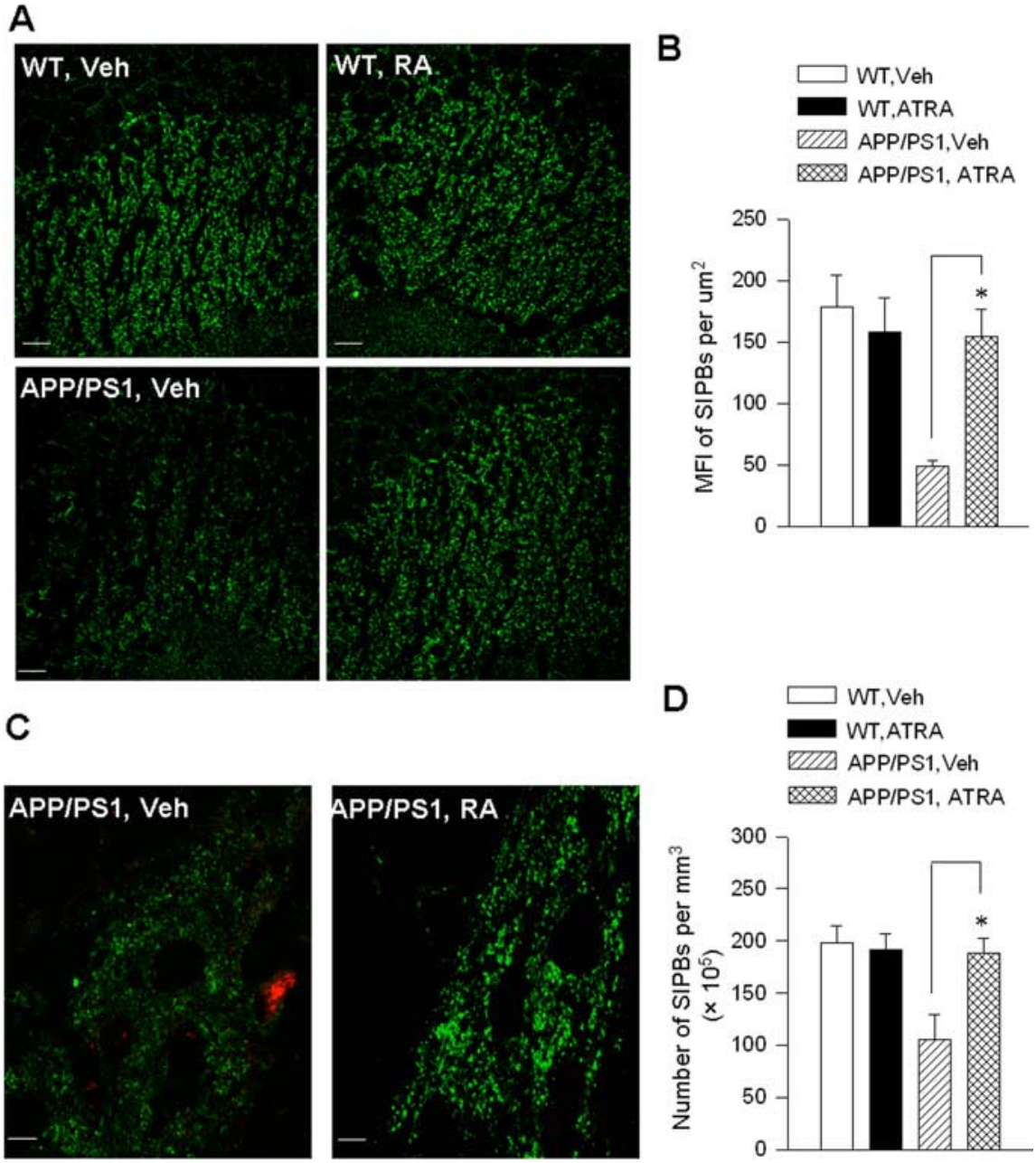

Figure 5. ATRA treatment prevents loss of presynaptic terminals in the brains of APP/PS1 mice. $A$, Fluorescent SYN immunostaining in the hippocampal CA3 region of APP/PS1 mice and wild-type mice (WT) treated with vehicle (Veh) or ATRA. Scale bar, $20 \mu \mathrm{m} . B$, Quantification of SYN immunoreactivity in the hippocampus. Mean value of each animal per group is the average of two to three experiments (total of 3-6 sections). Error bars represent means \pm SEM from six mice per group. $\boldsymbol{C}$ Double immunostaining of SYN (green) and A $\beta$ plaques (red) showed loss of SIPBs surrounding the $A \beta$ plaques in the hippocamdentate gyrus of the vehicle-treated APP/PS1 mice (left). In contrast, the ATRA-treated APP/PS1 mice (right) showed more significant integrity of SIPBs in the hippocampal dentate gyrus in which no plaques were observed (right). Scale bar, $20 \mu \mathrm{m}$. D, values from two to three experiments (total of $3-6$ sections). Error bars represent means \pm SEM from six mice per group. ${ }^{*} p<$ 0.05 versus vehicle-treated control APP/PS1 mice.

Another interesting finding of the present study is the significant inhibition of tau hyperphosphorylation by the ATRA treatment. Although both CDK5 and GSK3 $\beta$ are believed to be the most important kinases that regulate tau phosphorylation in the brain (Lovestone and Reynolds, 1997), our results demonstrated that CDK5, rather than GSK3 $\beta$, was predominantly inhibited by ATRA, suggesting that ATRA attenuates tau phosphorylation primarily through the inhibition of CDK5. Compatible with this result, we observed that CDK5 phosphorylation sites were more susceptible to the ATRA treatment than GSK3 $\beta$ sites on tau. For instance, among the several phosphorylation sites tested, e.g., Ser235, Ser396, Ser404, Ser519, and Thr205, the phosphorylation of tau at Ser396, which is catalyzed by GSK3 $\beta$ rather than CDK5 (Li and Paudel, 2006; Wang et al., 2007), was attenuated to a less extent by the ATRA treatment than other phosphorylation sites. The mechanisms behind the inhibitory role of ATRA in CDK5 activity are largely unknown. In addition to a possible direct influence on CDK5 activation, ATRA may inhibit CDK5 through 
stabilizing APP. Because APP has been shown to reciprocally regulate CDK5 activity (Han et al., 2005), ATRA-induced inhibition of APP processing observed in APP/PS1 mice may cause an enhanced stability of APP, thereby resulting in indirect inhibition of CDK5 activity and attenuation of tau phosphorylation.

Given the central role of fibrillar $A \beta$ in the activation of microglia and astrocytes seen in AD brain (Rozemuller et al., 2005) and in AD animal models (Frautschy et al., 1998; Apelt and Schliebs, 2001; Matsuoka et al., 2001), the significant decrease in activated microglia and astrocytes seen in the ATRA-treated APP/PS1 mice can be attributed to its inhibition of $A \beta$ accumulation. However, ATRA appears to possess an inherent anti-inflammatory function independent of A $\beta$ (Mehta et al., 1994; Datta et al., 2001). Although the underlying mechanisms remain largely unclear, ATRA-mediated inhibition of nuclear factor $-\kappa \mathrm{B}$ may play a role in this process (Choi et al., 2005; Dheen et al., 2005). Nevertheless, because brain inflammation is a risk factor for neurodegenerative disease, the anti-inflammatory effect of ATRA in the AD model mouse provides additional evidence for its therapeutic potential for AD.

We observed that ATRA treatment of the APP/PS1 mice significantly attenuated impairment of neuronal integrity compared with the vehicle treatment. SYN, a protein localized in the neuronal synaptic vesicles, has been shown to be decreased in the AD brain and correlated with the severity of cognitive deficits (Terry et al., 1991; Masliah et al., 1993). However, in transgenic APP mouse models, SYN is either reduced or unchanged (Irizarry et al., 1997; Hsia et al., 1999), likely attributable to different levels of transgenic APP and different stages of the neurodegenerative process. In this study, a significant decrease in SYN immunoreactivity was observed in the stratum lucidum of the CA3 area in the brains of the vehicle-treated APP/PS1 mice compared with the vehicletreated wild-type mice, and a significant reversal of this decrease was observed in the ATRA-treated APP/PS1 mice. ATRAmediated prevention of synaptic loss in the stratum lucidum of the CA3 area, in which the mossy fibers from the dentate gyrus synapse with the dendrites of the pyramidal neurons, may play a key role in rescuing deficits of learning and memory, because alterations in the distribution of mossy fibers are related to neuronal plasticity and long-term memory (Cremer et al., 1998; Ramirez-Amaya et al., 2001).

In support of the results with SYN, ATRA-treated APP/PS1
A
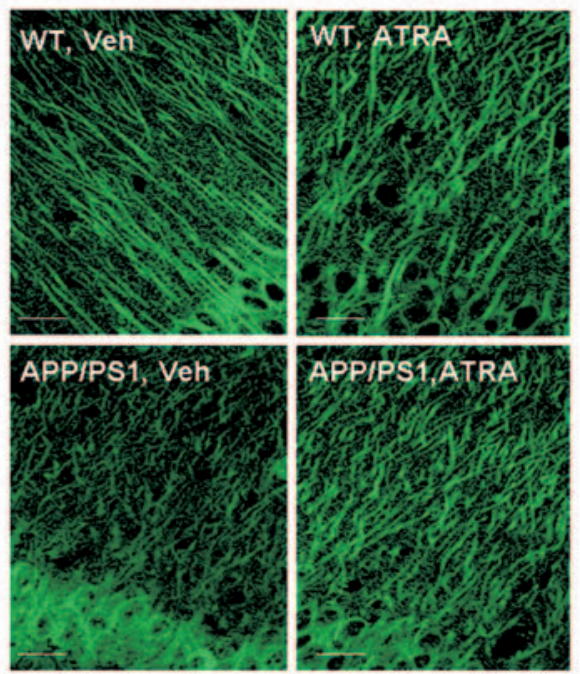

C

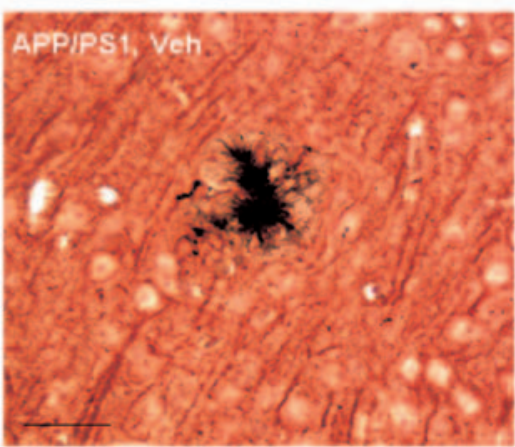

D
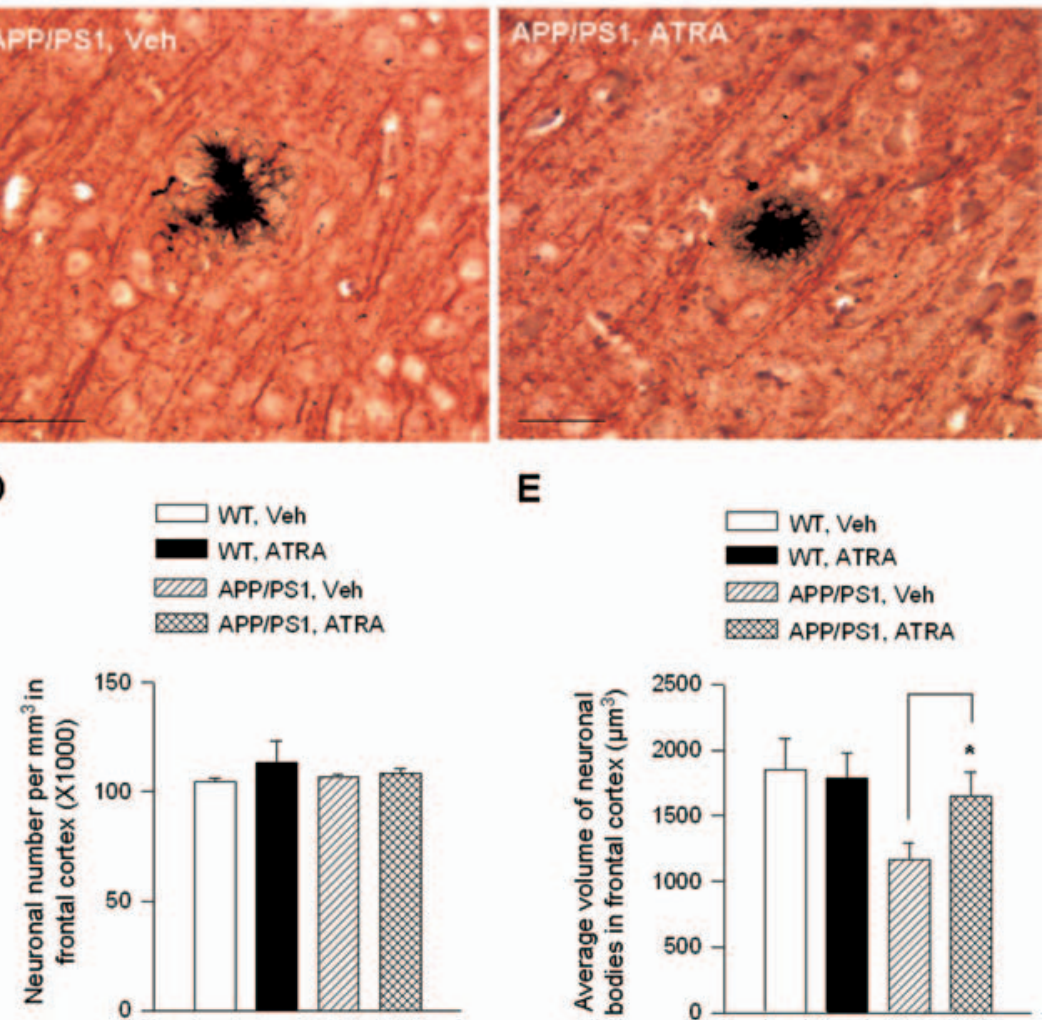

E
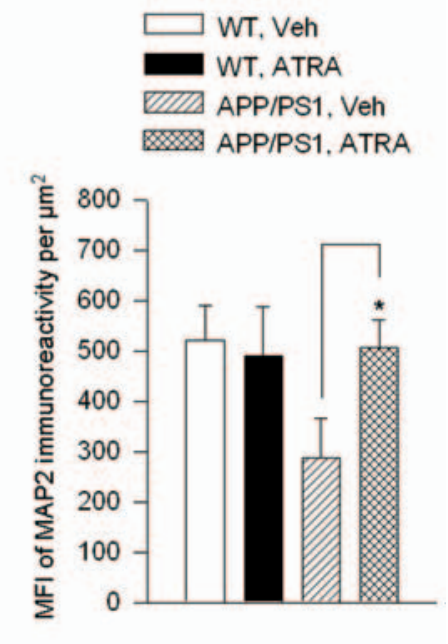

B

(1) 
A

$$
\begin{aligned}
& -\infty W T, \operatorname{Veh}(n=8) \\
& \longleftarrow \text { WT, ATRA }(n=8) \\
& \square-\operatorname{APPIPS1}, \operatorname{Veh}(n=8) \\
& \rightarrow \operatorname{APPIPS} 1, \operatorname{ATRA}(n=8)
\end{aligned}
$$

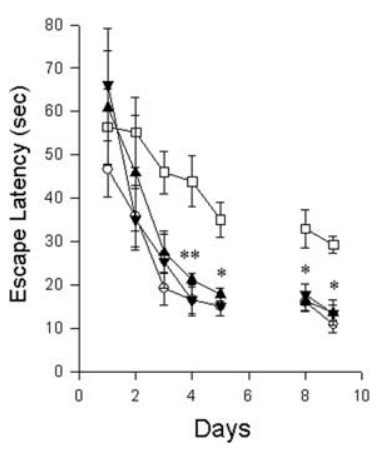

Figure 7. Chronic ATRA treatment of APP/PS1 mice results in attenuation of AD-type spatial memory deterioration. $\boldsymbol{A}$, Acquisition of spatial learning in the Morris water maze hiddenplatform task. Learning deficits in the control vehicle (Veh)-treated control APP/PS1 mice were ameliorated in the ATRA-treated APP/PS1 mice. Latency score represents time taken to escape to the platform from the water. Lines represent mean \pm SEM from six to eight mice (indicated) per group. $\boldsymbol{B}$, Memory test in Morris water maze probe trial without platform. Note that the deficits in the vehicle-treated APP/PS1 mice were improved in the ATRA-treated APP/PS1 mice. Error bars represent mean \pm SEM from six to eight mice (indicated) per group. ${ }^{*} p<0.05$, ${ }^{* *} p<0.01$ versus vehicle-treated control APP/PS1 mice. WT, Wild type.

APP/PS1 mice, a discrete neuronal loss is associated with $\mathrm{A} \beta$ plaques (Calhoun et al., 1998). Consistent with this result, we observed degenerative neurons surrounding the $A \beta$ plaques in the APP/PS1 mice treated with vehicle. In the ATRA-treated $\mathrm{APP} / \mathrm{PS} 1$ mice, $\mathrm{A} \beta$ deposits were significantly smaller, and, correspondingly, the extent of neuronal loss was much lower compared with the vehicle-treated APP/PS1 mice. The neuroprotective effect of ATRA seen in APP/PS1 mice is in line with a previous report showing protection against $\mathrm{A} \beta$-induced injury of primary hippocampal neuronal cultures (Sahin et al., 2005).

We demonstrate that ATRA treatment of APP/PS1 transgenic mice reverses cognitive deficits. As reported, excessive $A \beta$ accumulation is associated with disturbed cognitive function in an AD mouse model (Chen et al., 2000), and hyperphosphorylated tau leads to memory deficits and loss of functional synapses in a transgenic mouse model (Schindowski et al., 2006). The beneficial effect of ATRA on cognitive improvement in APP/PS1 mice is likely attributable to the combined effects of decreased levels of toxic $\mathrm{A} \beta$ peptides, tau hyperphosphorylation, and neurodegeneration. However, we cannot exclude the possibility that ATRA improves the learning and memory in a manner independent of decreasing $A \beta$ accumulation and tau hyperphosphorylation, because a previous study has shown that RA treatment of naturally aged mice alleviated age-related deficits in the CA1 LTP and completely alleviated their memory deficits (Etchamendy et al., 2001). The mechanism by which ATRA regulates spatial memory has not been delineated. The cholinergic (ACh) system is a potential target of retinoids, because RA increases the levels of choline acetyltransferase (ChAT) (Berse and Blusztajn, 1995), the enzyme that synthesizes ACh. Because the loss of ChAT-expressing neurons is characteristic of $\mathrm{AD}$ (Whitehouse et al., 1982), and because ATRA overcomes the reduction in ChAT induced by A $\beta$ peptides (Sahin et al., 2005), it is possible that ATRA may act as a neuroprotective agent in $\mathrm{AD}$ by restoring ChAT levels.

Together, the present study provides evidence that ATRA is able to attenuate $A \beta$-associated neuropathology and memory deficits in a APP/PS1 transgenic AD mouse model. ATRA is a small molecule that readily enters tissues and is concentrated in the brain compartments when administrated systemically (Kurlandsky et al., 1995; Le Doze et al., 2000). As an existing U.S. Pharmacopoeia drug, its toxicology profile has been well established, so the initiation of clinical trials could be accelerated.

\section{References}

Anderton BH, Betts J, Blackstock WP, Brion JP, Chapman S, Connell J, Dayanandan R, Gallo JM, Gibb G, Hanger DP, Hutton M, Kardalinou E, Leroy K, Lovestone S, Mack T, Reynolds CH, Van Slegtenhorst M (2001) Sites of phosphorylation in tau and factors affecting their regulation. Biochem Soc Symp 73-80.

Apelt J, Schliebs R (2001) Beta-amyloid-induced glial expression of both pro- and anti-inflammatory cytokines in cerebral cortex of aged transgenic Tg2576 mice with Alzheimer plaque pathology. Brain Res 894:21-30.

Aplin AE, Gibb GM, Jacobsen JS, Gallo JM, Anderton BH (1996) In vitro phosphorylation of the cytoplasmic domain of the amyloid precursor protein by glycogen synthase kinase-3beta. J Neurochem 67:699-707.

Berse B, Blusztajn JK (1995) Coordinated up-regulation of choline acetyltransferase and vesicular acetylcholine transporter gene expression by the retinoic acid receptor alpha, cAMP, and leukemia inhibitory factor/ciliary neurotrophic factor signaling pathways in a murine septal cell line. J Biol Chem 270:22101-22104.

Blanchard V, Moussaoui S, Czech C, Touchet N, Bonici B, Planche M, Canton T, Jedidi I, Gohin M, Wirths O, Bayer TA, Langui D, Duyckaerts C, Tremp G, Pradier L (2003) Time sequence of maturation of dystrophic neurites associated with Abeta deposits in APP/PS1 transgenic mice. Exp Neurol 184:247-263.

Bornemann KD, Wiederhold KH, Pauli C, Ermini F, Stalder M, Schnell L, Sommer B, Jucker M, Staufenbiel M (2001) Abeta-induced inflammatory processes in microglia cells of APP23 transgenic mice. Am J Pathol 158:63-73.

Calhoun ME, Wiederhold KH, Abramowski D, Phinney AL, Probst A, Sturchler-Pierrat C, Staufenbiel M, Sommer B, Jucker M (1998) Neuron loss in APP transgenic mice. Nature 395:755-756.

Chang KA, Kim HS, Ha TY, Ha JW, Shin KY, Jeong YH, Lee JP, Park CH, Kim S, Baik TK, Suh YH (2006) Phosphorylation of amyloid precursor protein (APP) at Thr668 regulates the nuclear translocation of the APP intracellular domain and induces neurodegeneration. Mol Cell Biol 26:4327-4338.

Chen G, Chen KS, Knox J, Inglis J, Bernard A, Martin SJ, Justice A, McConlogue L, Games D, Freedman SB, Morris RG (2000) A learning deficit related to age and beta-amyloid plaques in a mouse model of Alzheimer's disease. Nature 408:975-979.

Chiang MY, Misner D, Kempermann G, Schikorski T, Giguère V, Sucov HM, Gage FH, Stevens CF, Evans RM (1998) An essential role for retinoid receptors RARbeta and RXRgamma in long-term potentiation and depression. Neuron 21:1353-1361.

Choi WH, Ji KA, Jeon SB, Yang MS, Kim H, Min KJ, Shong M, Jou I, Joe EH (2005) Anti-inflammatory roles of retinoic acid in rat brain astrocytes: Suppression of interferon-gamma-induced JAK/STAT phosphorylation. Biochem Biophys Res Commun 329:125-131.

Cocco S, Diaz G, Stancampiano R, Diana A, Carta M, Curreli R, Sarais L, Fadda F (2002) Vitamin A deficiency produces spatial learning and memory impairment in rats. Neuroscience 115:475-482.

Cohen P, Frame S (2001) The renaissance of GSK3. Nat Rev Mol Cell Biol 2:769-776

Corcoran JP, So PL, Maden M (2004) Disruption of the retinoid signalling pathway causes a deposition of amyloid beta in the adult rat brain. Eur J Neurosci 20:896-902.

Cremer H, Chazal G, Carleton A, Goridis C, Vincent JD, Lledo PM (1998) Long-term but not short-term plasticity at mossy fiber synapses is impaired in neural cell adhesion molecule-deficient mice. Proc Natl Acad Sci U S A 95:13242-13247.

Cruz JC, Kim D, Moy LY, Dobbin MM, Sun X, Bronson RT, Tsai LH (2006) p25/cyclin-dependent kinase 5 induces production and intraneuronal accumulation of amyloid $\beta$ in vivo. J Neurosci 26:10536-10541.

Culvenor JG, Evin G, Cooney MA, Wardan H, Sharples RA, Maher F, Reed G, Diehlmann A, Weidemann A, Beyreuther K, Masters CL (2000) Prese- 
nilin 2 expression in neuronal cells: induction during differentiation of embryonic carcinoma cells. Exp Cell Res 255:192-206.

Datta PK, Reddy RS, Lianos EA (2001) Effects of all-trans-retinoic acid (atRA) on inducible nitric oxide synthase (iNOS) activity and transforming growth factor beta-1 production in experimental anti-GBM antibodymediated glomerulonephritis. Inflammation 25:351-359.

De Strooper B, Saftig P, Craessaerts K, Vanderstichele H, Guhde G, Annaert W, Von Figura K, Van Leuven F (1998) Deficiency of presenilin-1 inhibits the normal cleavage of amyloid precursor protein. Nature 391:387-390.

Dheen ST, Jun Y, Yan Z, Tay SS, Ling EA (2005) Retinoic acid inhibits expression of TNF-alpha and iNOS in activated rat microglia. Glia 50:21-31.

Edbauer D, Winkler E, Regula JT, Pesold B, Steiner H, Haass C (2003) Reconstitution of gamma-secretase activity. Nat Cell Biol 5:486-488.

Etchamendy N, Enderlin V, Marighetto A, Vouimba RM, Pallet V, Jaffard R, Higueret P (2001) Alleviation of a selective age-related relational memory deficit in mice by pharmacologically induced normalization of brain retinoid signaling. J Neurosci 21:6423-6429.

Etchamendy N, Enderlin V, Marighetto A, Pallet V, Higueret P, Jaffard R (2003) Vitamin A deficiency and relational memory deficit in adult mice: relationships with changes in brain retinoid signalling. Behav Brain Res 145:37-49.

Evin G, Zhu A, Holsinger RM, Masters CL, Li QX (2003) Proteolytic processing of the Alzheimer's disease amyloid precursor protein in brain and platelets. J Neurosci Res 74:386-392.

Fonseca MI, Zhou J, Botto M, Tenner AJ (2004) Absence of C1q leads to less neuropathology in transgenic mouse models of Alzheimer's disease. J Neurosci 24:6457-6465.

Frautschy SA, Horn DL, Sigel JJ, Harris-White ME, Mendoza JJ, Yang F, Saido TC, Cole GM (1998) Protease inhibitor coinfusion with amyloid $\beta$-protein results in enhanced deposition and toxicity in rat brain. J Neurosci 18:8311-8321.

Goodman AB (2006) Retinoid receptors, transporters, and metabolizers as therapeutic targets in late onset Alzheimer disease. J Cell Physiol 209:598-603.

Goodman AB, Pardee AB (2003) Evidence for defective retinoid transport and function in late onset Alzheimer's disease. Proc Natl Acad Sci U S A 100:2901-2905.

Götz J, Chen F, van Dorpe J, Nitsch RM (2001) Formation of neurofibrillary tangles in P301l tau transgenic mice induced by Abeta 42 fibrils. Science 293:1491-1495.

Gundersen HJ, Jensen EB (1987) The efficiency of systematic sampling in stereology and its prediction. J Microsc 147:229-263.

Han P, Dou F, Li F, Zhang X, Zhang YW, Zheng H, Lipton SA, Xu H, Liao FF (2005) Suppression of cyclin-dependent kinase 5 activation by amyloid precursor protein: a novel excitoprotective mechanism involving modulation of tau phosphorylation. J Neurosci 25:11542-11552.

Hanger DP, Betts JC, Loviny TL, Blackstock WP, Anderton BH (1998) New phosphorylation sites identified in hyperphosphorylated tau (paired helical filament-tau) from Alzheimer's disease brain using nanoelectrospray mass spectrometry. J Neurochem 71:2465-2476.

Hong CS, Caromile L, Nomata Y, Mori H, Bredesen DE, Koo EH (1999) Contrasting role of presenilin-1 and presenilin-2 in neuronal differentiation in vitro. J Neurosci 19:637-643.

Hsia AY, Masliah E, McConlogue L, Yu GQ, Tatsuno G, Hu K, Kholodenko D, Malenka RC, Nicoll RA, Mucke L (1999) Plaque-independent disruption of neural circuits in Alzheimer's disease mouse models. Proc Natl Acad Sci U S A 96:3228-3233.

Husson M, Enderlin V, Delacourte A, Ghenimi N, Alfos S, Pallet V, Higueret P (2006) Retinoic acid normalizes nuclear receptor mediated hypoexpression of proteins involved in beta-amyloid deposits in the cerebral cortex of vitamin A deprived rats. Neurobiol Dis 23:1-10.

Iijima K, Ando K, Takeda S, Satoh Y, Seki T, Itohara S, Greengard P, Kirino Y, Nairn AC, Suzuki T (2000) Neuron-specific phosphorylation of Alzheimer's beta-amyloid precursor protein by cyclin-dependent kinase 5 . J Neurochem 75:1085-1091.

Imahori K, Uchida T (1997) Physiology and pathology of tau protein kinases in relation to Alzheimer's disease. J Biochem 121:179-188.

Iqbal K, Alonso Adel C, Chen S, Chohan MO, El-Akkad E, Gong CX, Khatoon S, Li B, Liu F, Rahman A, Tanimukai H, Grundke-Iqbal I (2005) Tau pathology in Alzheimer disease and other tauopathies. Biochim Biophys Acta 1739:198-210.

Irizarry MC, McNamara M, Fedorchak K, Hsiao K, Hyman BT (1997) APPSw transgenic mice develop age-related A beta deposits and neuropil abnormalities, but no neuronal loss in CA1. J Neuropathol Exp Neurol 56:965-973.

Itagaki S, McGeer PL, Akiyama H, Zhu S, Selkoe D (1989) Relationship of microglia and astrocytes to amyloid deposits of Alzheimer disease. J Neuroimmunol 24:173-182.

Iyoda M, Hudkins KL, Wietecha TA, Banas MC, Guo S, Liu G, Wang L, Kowalewska J, Alpers CE (2007) All-trans-retinoic acid aggravates cryoglobulin-associated membranoproliferative glomerulonephritis in mice. Nephrol Dial Transplant 22:3451-3461.

Jankowsky JL, Slunt HH, Ratovitski T, Jenkins NA, Copeland NG, Borchelt DR (2001) Co-expression of multiple transgenes in mouse CNS: a comparison of strategies. Biomol Eng 17:157-165.

Jankowsky JL, Fadale DJ, Anderson J, Xu GM, Gonzales V, Jenkins NA, Copeland NG, Lee MK, Younkin LH, Wagner SL, Younkin SG, Borchelt DR (2004) Mutant presenilins specifically elevate the levels of the 42 residue beta-amyloid peptide in vivo: evidence for augmentation of a 42 -specific gamma secretase. Hum Mol Genet 13:159-170.

Johnson GV, Hartigan JA (1999) Tau protein in normal and Alzheimer's disease brain: an update. J Alzheimers Dis 1:329-351.

Kalin JR, Starling ME, Hill DL (1981) Disposition of all-trans-retinoic acid in mice following oral doses. Drug Metab Dispos 9:196-201.

Kurlandsky SB, Gamble MV, Ramakrishnan R, Blaner WS (1995) Plasma delivery of retinoic acid to tissues in the rat. J Biol Chem 270:17850-17857.

Kurt MA, Davies DC, Kidd M, Duff K, Howlett DR (2003) Hyperphosphorylated tau and paired helical filament-like structures in the brains of mice carrying mutant amyloid precursor protein and mutant presenilin-1 transgenes. Neurobiol Dis 14:89-97.

Lahiri S, Buerk DG, Chugh D, Osanai S, Mokashi A (1995) Reciprocal photolabile $\mathrm{O} 2$ consumption and chemoreceptor excitation by carbon monoxide in the cat carotid body: evidence for cytochrome a3 as the primary O2 sensor. Brain Res 684:194-200.

Le Doze F, Debruyne D, Albessard F, Barre L, Defer GL (2000) Pharmacokinetics of all-trans retinoic acid, 13-cis retinoic acid, and fenretinide in plasma and brain of rat. Drug Metab Dispos 28:205-208.

Lee MS, Kao SC, Lemere CA, Xia W, Tseng HC, Zhou Y, Neve R, Ahlijanian MK, Tsai LH (2003) APP processing is regulated by cytoplasmic phosphorylation. J Cell Biol 163:83-95.

Li T, Paudel HK (2006) Glycogen synthase kinase 3beta phosphorylates Alzheimer's disease-specific Ser396 of microtubule-associated protein tau by a sequential mechanism. Biochemistry 45:3125-3133.

Liu F, Su Y, Li B, Zhou Y, Ryder J, Gonzalez-DeWhitt P, May PC, Ni B (2003) Regulation of amyloid precursor protein (APP) phosphorylation and processing by p35/Cdk5 and p25/Cdk5. FEBS Lett 547:193-196.

Lovestone S, Reynolds CH (1997) The phosphorylation of tau: a critical stage in neurodevelopment and neurodegenerative processes. Neuroscience 78:309-324.

Maden M (2007) Retinoic acid in the development, regeneration and maintenance of the nervous system. Nat Rev Neurosci 8:755-765.

Mangelsdorf DJ, Evans RM (1995) The RXR heterodimers and orphan receptors. Cell 83:841-850.

Masliah E, Miller A, Terry RD (1993) The synaptic organization of the neocortex in Alzheimer's disease. Med Hypotheses 41:334-340.

Matsuoka Y, Picciano M, Malester B, LaFrancois J, Zehr C, Daeschner JM, Olschowka JA, Fonseca MI, O’Banion MK, Tenner AJ, Lemere CA, Duff K (2001) Inflammatory responses to amyloidosis in a transgenic mouse model of Alzheimer's disease. Am J Pathol 158:1345-1354.

McGeer EG, McGeer PL (1999) Brain inflammation in Alzheimer disease and the therapeutic implications. Curr Pharm Des 5:821-836.

Mehta K, McQueen T, Tucker S, Pandita R, Aggarwal BB (1994) Inhibition by all-trans-retinoic acid of tumor necrosis factor and nitric oxide production by peritoneal macrophages. J Leukoc Biol 55:336-342.

Misner DL, Jacobs S, Shimizu Y, de Urquiza AM, Solomin L, Perlmann T, De Luca LM, Stevens CF, Evans RM (2001) Vitamin A deprivation results in reversible loss of hippocampal long-term synaptic plasticity. Proc Natl Acad Sci U S A 98:11714-11719.

Moolman DL, Vitolo OV, Vonsattel JP, Shelanski ML (2004) Dendrite and 
dendritic spine alterations in Alzheimer models. J Neurocytol 33:377-387.

Morishima-Kawashima M, Hasegawa M, Takio K, Suzuki M, Yoshida H, Titani K, Ihara Y (1995) Proline-directed and non-proline-directed phosphorylation of PHF-tau. J Biol Chem 270:823-829.

Morris R (1984) Developments of a water-maze procedure for studying spatial learning in the rat. J Neurosci Methods 11:47-60.

Neve RL, Rogers J, Higgins GA (1990) The Alzheimer amyloid precursorrelated transcript lacking the beta/A4 sequence is specifically increased in Alzheimer's disease brain. Neuron 5:329-338.

Ohno M, Chang L, Tseng W, Oakley H, Citron M, Klein WL, Vassar R, Disterhoft JF (2006) Temporal memory deficits in Alzheimer's mouse models: rescue by genetic deletion of BACE1. Eur J Neurosci 23:251-260.

Ono K, Yoshiike Y, Takashima A, Hasegawa K, Naiki H, Yamada M (2004) Vitamin A exhibits potent antiamyloidogenic and fibril-destabilizing effects in vitro. Exp Neurol 189:380-392.

Ramírez-Amaya V, Balderas I, Sandoval J, Escobar ML, Bermúdez-Rattoni F (2001) Spatial long-term memory is related to mossy fiber synaptogenesis. J Neurosci 21:7340-7348.

Rozemuller AJ, van Gool WA, Eikelenboom P (2005) The neuroinflammatory response in plaques and amyloid angiopathy in Alzheimer's disease: therapeutic implications. Curr Drug Targets CNS Neurol Disord 4:223-233.

Rutten BP, Van der Kolk NM, Schafer S, van Zandvoort MA, Bayer TA, Steinbusch HW, Schmitz C (2005) Age-related loss of synaptophysin immunoreactive presynaptic boutons within the hippocampus of APP751SL, PS1M146L, and APP751SL/PS1M146L transgenic mice. Am J Pathol 167:161-173.

Sahin M, Karauzum SB, Perry G, Smith MA, Aliciguzel Y (2005) Retinoic acid isomers protect hippocampal neurons from amyloid-beta induced neurodegeneration. Neurotox Res 7:243-250.

Satoh J, Kuroda Y (2000) Amyloid precursor protein beta-secretase (BACE) mRNA expression in human neural cell lines following induction of neuronal differentiation and exposure to cytokines and growth factors. Neuropathology 20:289-296.

Schindowski K, Bretteville A, Leroy K, Bégard S, Brion JP, Hamdane M, Buée L (2006) Alzheimer's disease-like tau neuropathology leads to memory deficits and loss of functional synapses in a novel mutated tau transgenic mouse without any motor deficits. Am J Pathol 169:599-616.

Selkoe DJ (2001) Alzheimer's disease results from the cerebral accumulation and cytotoxicity of amyloid beta-protein. J Alzheimers Dis 3:75-80.

Sergeant N, David JP, Champain D, Ghestem A, Wattez A, Delacourte A (2002) Progressive decrease of amyloid precursor protein carboxy terminal fragments (APP-CTFs), associated with tau pathology stages, in Alzheimer's disease. J Neurochem 81:663-672.

Sharma P, Sharma M, Amin ND, Albers RW, Pant HC (1999) Regulation of cyclin-dependent kinase 5 catalytic activity by phosphorylation. Proc Natl Acad Sci U S A 96:11156-11160.

Shelton SB, Johnson GV (2004) Cyclin-dependent kinase-5 in neurodegeneration. J Neurochem 88:1313-1326.

Singh TJ, Grundke-Iqbal I, McDonald B, Iqbal K (1994) Comparison of the phosphorylation of microtubule-associated protein tau by non-proline dependent protein kinases. Mol Cell Biochem 131:181-189.

Stalder M, Phinney A, Probst A, Sommer B, Staufenbiel M, Jucker M (1999) Association of microglia with amyloid plaques in brains of APP23 transgenic mice. Am J Pathol 154:1673-1684.

Standen CL, Brownlees J, Grierson AJ, Kesavapany S, Lau KF, McLoughlin DM, Miller CC (2001) Phosphorylation of thr(668) in the cytoplasmic domain of the Alzheimer's disease amyloid precursor protein by stressactivated protein kinase $1 \mathrm{~b}$ (Jun N-terminal kinase-3). J Neurochem 76:316-320.

Stokin GB, Lillo C, Falzone TL, Brusch RG, Rockenstein E, Mount SL, Raman R, Davies P, Masliah E, Williams DS, Goldstein LS (2005) Axonopathy and transport deficits early in the pathogenesis of Alzheimer's disease. Science 307:1282-1288.

Suzuki N, Cheung TT, Cai XD, Odaka A, Otvos L Jr, Eckman C, Golde TE, Younkin SG (1994) An increased percentage of long amyloid beta protein secreted by familial amyloid beta protein precursor (beta APP717) mutants. Science 264:1336-1340.

Terry RD, Masliah E, Salmon DP, Butters N, DeTeresa R, Hill R, Hansen LA, Katzman R (1991) Physical basis of cognitive alterations in Alzheimer's disease: synapse loss is the major correlate of cognitive impairment. Ann Neurol 30:572-580.

Trinchese F, Liu S, Battaglia F, Walter S, Mathews PM, Arancio O (2004) Progressive age-related development of Alzheimer-like pathology in APP/ PS1 mice. Ann Neurol 55:801-814.

Vassar R, Bennett BD, Babu-Khan S, Kahn S, Mendiaz EA, Denis P, Teplow DB, Ross S, Amarante P, Loeloff R, Luo Y, Fisher S, Fuller J, Edenson S, Lile J, Jarosinski MA, Biere AL, Curran E, Burgess T, Louis JC, Collins F, Treanor J, Rogers G, Citron M (1999) Beta-secretase cleavage of Alzheimer's amyloid precursor protein by the transmembrane aspartic protease BACE. Science 286:735-741.

Walsh DM, Klyubin I, Fadeeva JV, Cullen WK, Anwyl R, Wolfe MS, Rowan MJ, Selkoe DJ (2002) Naturally secreted oligomers of amyloid beta protein potently inhibit hippocampal long-term potentiation in vivo. Nature 416:535-539.

Wang CC, Campbell S, Furner RL, Hill DL (1980) Disposition of all-transand 13-cis-retinoic acids and n-hydroxyethylretinamide in mice after intravenous administration. Drug Metab Dispos 8:8-11.

Wang JZ, Wu Q, Smith A, Grundke-Iqbal I, Iqbal K (1998) Tau is phosphorylated by GSK-3 at several sites found in Alzheimer disease and its biological activity markedly inhibited only after it is prephosphorylated by A-kinase. FEBS Lett 436:28-34.

Wang JZ, Grundke-Iqbal I, Iqbal K (2007) Kinases and phosphatases and tau sites involved in Alzheimer neurofibrillary degeneration. Eur J Neurosci 25:59-68.

Wen Y, Planel E, Herman M, Figueroa HY, Wang L, Liu L, Lau LF, Yu WH, Duff KE (2008a) Interplay between cyclin-dependent kinase 5 and glycogen synthase kinase 3 beta mediated by neuregulin signaling leads to differential effects on tau phosphorylation and amyloid precursor protein processing. J Neurosci 28:2624-2632.

Wen Y, Yu WH, Maloney B, Bailey J, Ma J, Marié I, Maurin T, Wang L, Figueroa H, Herman M, Krishnamurthy P, Liu L, Planel E, Lau LF, Lahiri DK, Duff K (2008b) Transcriptional regulation of beta-secretase by p25/ cdk5 leads to enhanced amyloidogenic processing. Neuron 57:680-690.

West MJ, Coleman PD, Flood DG, Troncoso JC (1994) Differences in the pattern of hippocampal neuronal loss in normal ageing and Alzheimer's disease. Lancet 344:769-772.

Whitehouse PJ, Price DL, Struble RG, Clark AW, Coyle JT, Delon MR (1982) Alzheimer's disease and senile dementia: loss of neurons in the basal forebrain. Science 215:1237-1239.

Wietrzych M, Meziane H, Sutter A, Ghyselinck N, Chapman PF, Chambon P, Krezel W (2005) Working memory deficits in retinoid X receptor gamma-deficient mice. Learn Mem 12:318-326.

Wirenfeldt M, Dalmau I, Finsen B (2003) Estimation of absolute microglial cell numbers in mouse fascia dentata using unbiased and efficient stereological cell counting principles. Glia 44:129-139.

Yang Y, Quitschke WW, Brewer GJ (1998) Upregulation of amyloid precursor protein gene promoter in rat primary hippocampal neurons by phorbol ester, IL-1 and retinoic acid, but not by reactive oxygen species. Brain Res Mol Brain Res 60:40-49.

Zhang H, Gong B, Liu S, Fa' M, Ninan I, Staniszewski A, Arancio O (2005) Synaptic fatigue is more pronounced in the APP/PS1 transgenic mouse model of Alzheimer's disease. Curr Alzheimer Res 2:137-140.

Zhou XW, Gustafsson JA, Tanila H, Bjorkdahl C, Liu R, Winblad B, Pei JJ (2008) Tau hyperphosphorylation correlates with reduced methylation of protein phosphatase 2A. Neurobiol Dis 31:386-394. 